\title{
Role of interfacial water in adhesion, friction, and wear-A critical review
}

\author{
Lei CHEN, Linmao QIAN* \\ Tribology Research Institute, State Key Laboratory of Traction Power, Southwest Jiaotong University, Chengdu 610031, China \\ Received: 29 November 2019 / Revised: 20 March 2020 / Accepted: 07 May 2020 \\ (C) The author(s) 2020.
}

\begin{abstract}
Surficial water adsorption and interfacial water condensation as natural phenomena that can alter the contact status of the solid interface and tribological performances are crucial in all length scales, i.e., from earthquakes to skating at the macroscale level and even to micro/nano-electromechanical systems (M/NEMS) at the microscale/nanoscale level. Interfacial water exhibits diverse structure and properties from bulk water because of its further interaction with solid surfaces. In this paper, the evolutions of the molecular configuration of the adsorbed water layer depending on solid surface chemistry (wettability) and structure, environmental conditions (i.e., relative humidity and temperature), and experimental parameters (i.e., sliding speed and normal load) and their impacts on tribological performances, such as adhesion, friction, and wear, are systematically reviewed. Based on these factors, interfacial water can increase or reduce adhesion and friction as well as facilitate or suppress the tribochemical wear depending on the water condensation kinetics at the interface as well as the thickness and structure of the involved interfacial water.
\end{abstract}

Keywords: water adsorption; water condensation, adhesion; friction; tribochemical wear

\section{Introduction}

As one of the most common and earliest materials on earth, water usually adsorbs on most organic and inorganic surfaces unless it is completely chemically inert [1]. The unique bulk properties of liquid water originate from its large dipole moment and high polarizability, and individual water molecules also have hydrogen bonding capability [2, 3]. The formation of an ordered water layer on solid surfaces has been detected by experimental measurements [4,5] and computational simulations [6, 7]. This indicates that the adsorbed water on the solid surface may exhibit diverse structures or properties than those of liquid water because of the additional interaction with the solid surface [8-10]. It is well known that water adsorption on a solid contact interface involves the condensation of water bridge (or meniscus) [11], which may alter the contact state and further impact adhesion, friction, and wear performances [12, 13]. Understanding the structure of interfacial water and its role in tribological behaviors is fundamental.

With the integration and miniaturization of electronics and mechanical parts, tribological problems (e.g., high adhesion, friction, and severe wear) caused by surface/size effects and meniscus condensation have become increasingly prominent $[14,15]$. These severely affect the stability and lifetime of microdevices, such as hard disks and micro/nano-electromechanical systems (M/NEMS) [16, 17]. For instance, the final step in Si-based MEMS fabrication is the removal of the oxide sacrificial layer; however, the re-oxidation with surface hydrophilization occurs with exposure to water or humid air. This release process along

* Corresponding author: Linmao QIAN, E-mail: linmao@swjtu.edu.cn 


\section{Nomenclature}

\begin{tabular}{llll}
$F_{\mathrm{c}}$ & Capillary force & $h_{\mathrm{ice}}$ & Adsorbed ice-like water thickness \\
$F_{\mathrm{s}}$ & Surface tension force & $F_{\mathrm{t}}$ & Friction force \\
$F_{\mathrm{p}}$ & Force caused by pressure difference & $F_{\mathrm{n}}$ & Normal load \\
$\gamma$ & Water surface tension & $F_{\mathrm{a}}$ & Adhesion force \\
$\theta_{1}$ & Contact angle of ball surface & $\mu$ & Friction coefficient \\
$\theta_{2}$ & Contact angle of substrate & $V$ & Meniscus volume \\
$\phi$ & Filling angle of meniscus & $\Delta E(h)$ & Threshold free energy \\
$\phi_{\text {ice }}$ & Filling angle of ice-like meniscus & $k_{\mathrm{B}}$ & Boltzmann constant \\
$R$ & Ball or tip radius & $t$ & Condensation time of a meniscus \\
$H$ & Hamaker constant & $t_{\mathrm{a}}$ & Condensation time of a liquid monolayer \\
$r_{\mathrm{L}}$ & Meniscus radius & $\rho$ & Molecular density of the liquid \\
$r_{\mathrm{K}}$ & Kelvin radius & $\lambda$ & Full width of interstitial height distribution \\
$V_{0}$ & Volume of water molecule & $f(v)$ & Fraction of total number of meniscus \\
$a$ & Minimum sphere-plane separation & $v$ & Sliding speed \\
$F_{\mathrm{vdW}}$ & van der Waals force & $\tau$ & Wear rate \\
$F_{\text {ice }}$ & Ice-like meniscus rupture force & $f_{0}$ & Effective attempt frequency \\
$A$ & Cross-section area of meniscus & $\sigma$ & Contact stress \\
$A_{\text {ice }}$ & Cross-section area of ice-like meniscus & $b$ & Lattice parameter \\
$\delta$ & Lennard-Jones parameter & $\Delta U_{\text {act }}$ & Activation barrier \\
$H$ & Adsorbed water thickness & $\Delta V_{\text {act }}$ & Critical activation volume \\
$T$ & Absolute temperature & & \\
\hline & & & \\
\hline
\end{tabular}

with the enhancement of water adsorption increases the capillary-related adhesion force or "release adhesion", which may directly damage microdevices/ nanodevices [18, 19]. During the operation of nanodevices, the strong capillary interaction of the contact or near-contact nanostructure caused by the size and surface effects induces a high adhesion force (denoted as "in-use adhesion"). This also results in the sharp increase in the friction force and the exponential decrease in its lifetime [20,21]. Furthermore, the water condensation at a tribological interface may alter the wear mechanism, facilitating material failure. Surface wear is usually dominated by mechanical interaction, which initiates when the contact stress exceeds the yield strength of the material; it is followed by behaviors, such as plastic flow, crack propagation, or material removal [22-25]. The interfacial water may activate the tribochemical reaction of the sliding interface, leading to severe wear at an extremely low contact pressure. Under these conditions, the surface wear is mainly dominated by the atomic attrition and removal of softened materials generated by tribochemical reactions [26-30].

Recently, water-associated tribochemical wear has attracted considerable interest from the scientific community because of its critical role in the abovementioned M/NEMS applications and ultra-precision surface manufacturing, such as chemical mechanical polishing (CMP). The CMP aims to achieve a controllable atomic material removal by adjusting the related tribochemical reactions [31-33]. Previous studies have proved that the configurations involving the thickness and structure of interfacial water significantly influence tribochemical wear [34-36]. Considering the native oxide-covered silicon as an example, the interfacial water that forms at a low relative humidity $(\mathrm{RH})$ is dominated by an ordered structure and has a strongly hydrogen-bonded network. This can enhance the tribochemical reaction and facilitate the material removal of silicon. Conversely, the liquid-like water with a disordered structure that adsorbs under a high $\mathrm{RH}$ condition provides lubrication to reduce the tribochemical wear $[37,38]$. However, the configuration of interfacial water confined in the contact region not only depends on the intrinsic properties of the solid surface (e.g., wettability and atomic structure), but also depends on external environments and parameters (e.g., contact force, contact time or sliding speed, and temperature) in addition to humidity (Fig. 1) [39-42]. 

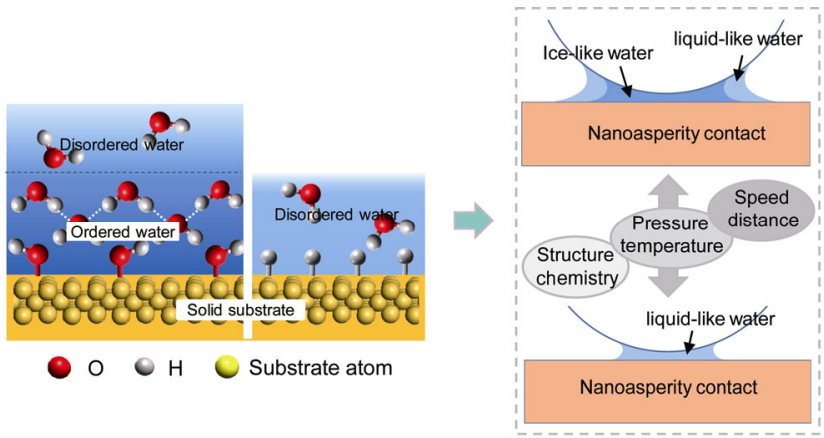

Fig. 1 Water adsorption on solid surface and water condensation at contact or near-contact interface: (a) water adsorption on solid surface with different configurations depending on surficial termination groups and water vapor pressures. (b) Schematic of water condensation at contact or near-contact asperity-contact interface depending on solid surface chemistry and structure, environments (i.e., vapor pressure and temperature), and experimental conditions (i.e., sliding speed and contact load).

In this paper, the configuration evolution of the adsorbed water layer on the solid and its impact on tribological performance (e.g., adhesion, friction, and wear) are systematically reviewed. The review considers the solid surface chemistry and structure, environmental conditions, and experimental parameters. According to these factors, the interfacial water is found to perform a crucial function in increasing or reducing adhesion and friction as well as facilitating or suppressing the tribochemical wear. This depends on the occurrence of water condensation between the contact interface and the evolution of the involved water configuration.

\section{Evolution of absorbed water configuration on solid surface}

Knowledge on interfacial water configuration near solid surfaces is crucial to understanding many important surficial problems involving water. These problems include the agglomeration of hydrophilic surfaces or macromolecules in water [43, 44], fabrication of uniform films in atomic layer deposition [45], highly capillary-related friction, and severe water-associated wear of solid materials [46-48]. Here, the evolution of the adsorbed water structure depending on the chemical properties and physical structure of solid surfaces as well as the surrounding atmosphere are reviewed based on the configuration of water molecules characterized by spectroscopic techniques or detected by computational simulations.

\subsection{Adsorption of ice-like water structure on solid surface}

As a result of the absence of compatible technology, computational simulations and numerical calculations $[49,50]$ were initially employed to study the interfacial water structure detected at the atomic scale. In the early $1990_{s}$, the development of infrared visible sum-frequency generation (SFG) provided a versatile surface spectroscopic tool to probe all types of interfaces, including liquid-liquid and solid-liquid interfaces [51, 52]. Du et al. [53] measured the SFG spectrum of the water layer adsorbed on the mica surface and observed two peaks in the region from 3,000 to $3,500 \mathrm{~cm}^{-1}$ because of the hydrogen-bonded $\mathrm{OH}$ stretching modes. The peak at $3,200 \mathrm{~cm}^{-1}$ is normally attributed to the in-phase vibrations of the coupled symmetric $\mathrm{OH}$ stretch mode of tetrahedrally coordinated water molecules. The domination of this peak in the ice spectrum indicates bond ordering (or formation of an ice-like structure) in the water molecular arrangement. Accordingly, another peak at $\sim 3,400 \mathrm{~cm}^{-1}$ caused by the symmetric stretch mode of the asymmetrically bonded water molecules represents the bond disordering in the water molecular arrangement. Based on the fact that the spectrum of the water layer adsorbed on the mica surface is dominated by the peak at $\sim 3,200$ $\mathrm{cm}^{-1}$, it was deduced that the interfacial water molecules are well bond-ordered, i.e., the adsorbed water layer has an ice-like structure. By using first-principle molecular dynamics (MD) simulation, Odelius et al. [54] confirmed that the water on the mica surface condensed into a fully connected two-dimensional (2D) hydrogen bond network, forming a monolayer ice-like water (Figs. 2(a) and 2(b)). The formations of the ordered structure were also experimentally observed on other material surfaces, such as silica [55], metal, and metal oxide [56-58]. These are found to be in fair agreement with those of the density functional theory (DFT) and MD simulations [59,60]. 

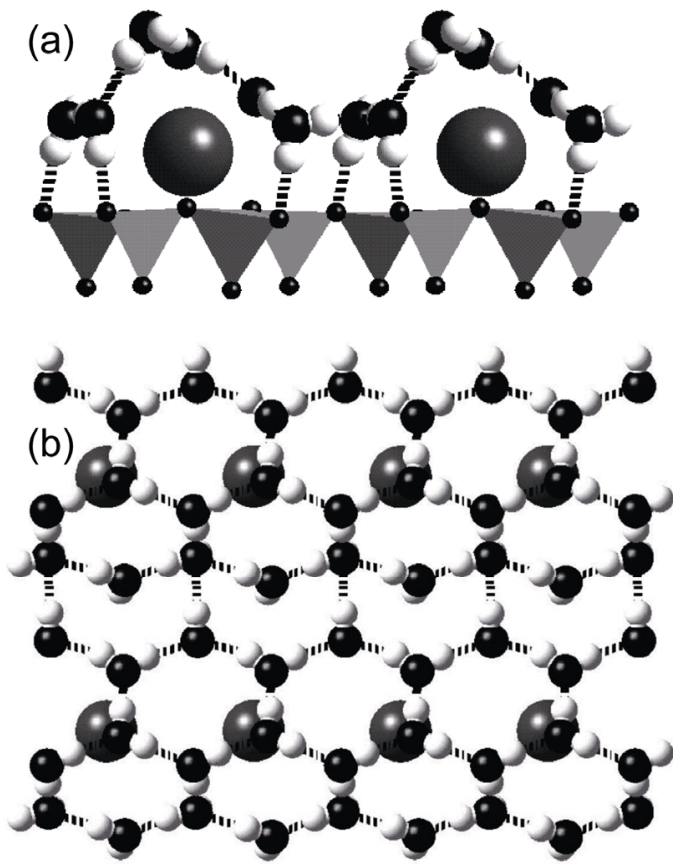

Fig. 2 (a) Side view and (b) top view of 2D ice structure of adsorbed water on mica surface. H-bond network consists of distorted hexagons. Reproduced with permission from Ref. [54], (C) American Physical Society 1997.

\subsection{Water adsorption depending on atmosphere and solid surface properties}

Based on the measurements using SFG spectroscopy or attenuated total reflection-infrared (ATR-IR) spectroscopy, it was found that the hydrophilic surfaces were covered by an ice-like water layer, and the water structure was dynamic depending on the partial water vapor pressure [61-63]. Asay et al. [61] presented the configuration of adsorbed water molecules on the fully hydroxylcovered silicon surface at various $\mathrm{RH}$ values. The evolution of water thickness and structure along with the RH was basically divided into three regions (Fig. 3). At a $\mathrm{RH}$ of less than $30 \%$ as the first region, the adsorbed water layer mainly grows exhibiting an ice-like structure; the growth rate becomes relatively high as the $\mathrm{RH}$ increases. In the middle region, at a $\mathrm{RH}$ range of $30 \%-60 \%$, the ice-like water remains dominant; however, the disordered water gradually starts to grow. In the last region, at a $\mathrm{RH}$ exceeding $60 \%$, ice-like water ceases to grow, and only the disordered water grows rapidly with the increase in $\mathrm{RH}$.

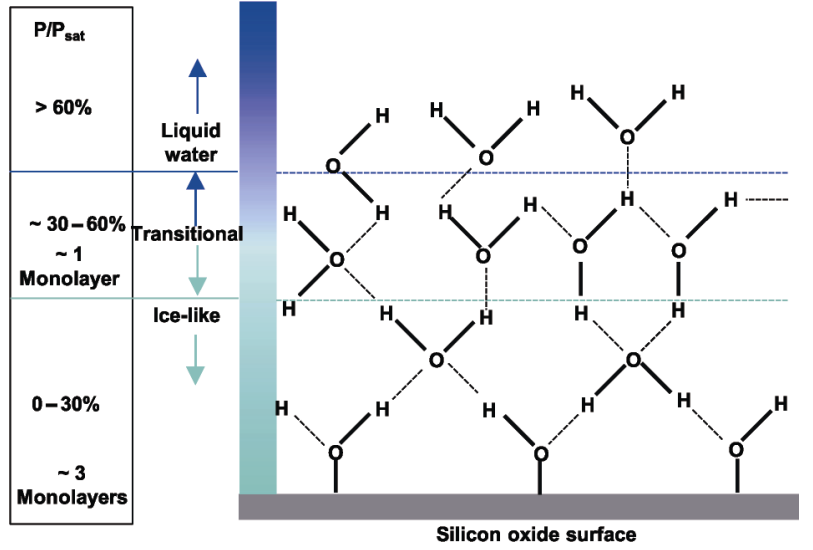

Fig. 3 Schematic of structural evolution of adsorbed water layer on hydrophilic silicon oxide surface. With the increase in $\mathrm{RH}$, three regions with $\mathrm{RH}=0-30 \%, \sim 30 \%$ $60 \%$, and $\mathrm{RH}>60 \%$ are defined to demonstrate the different structures of adsorbed water layer on silicon oxide surface. Reproduced with permission from Ref. [61], (C) American Chemical Society 2005.

Not only the above-mentioned environmental atmosphere, but also the surface chemistry and physical structures of solids significantly influence the interfacial water structure. For instance, the MD simulations demonstrated that no hydrogen bond interaction existed between the hydrophobic graphite surface and water. Moreover, the water molecules mainly exhibited a diffusive behavior [64, 65]. Asay et al. [66] controlled the surface wettability by changing the coverage rate of the surface silanol groups on the silicon surface and detected its effect on the adsorbed water thickness and structure using ATR-IR spectroscopy. Both the total thickness of the adsorbed water layer and amount of ice-like water decreased with the hydrophobization of solid surfaces along with the decrease in the concentration of the surface silanol groups. With the use of the same technology as the foregoing, Chen et al. [67] quantified the difference between the adsorbed water configuration on a hydrophilic hydroxyl-terminated silicon (Si/OH) surface $\left(<5^{\circ}\right)$ and a hydrophobic hydrogenterminated silicon $(\mathrm{Si} / \mathrm{H})$ surface $\left(\sim 85^{\circ}\right)$. The icelike spectrum is dominant (Fig. $4(\mathrm{a})$ ) at low $\mathrm{RH}$ values corresponding to the formation of the ordered structure on the Si/OH surface (Fig. 4(c)). This differs from the peak at $\sim 3,200 \mathrm{~cm}^{-1}$ in the ATR-IR spectrum caused by the strongly hydrogenbonded network, which is weak in the entire $\mathrm{RH}$ 

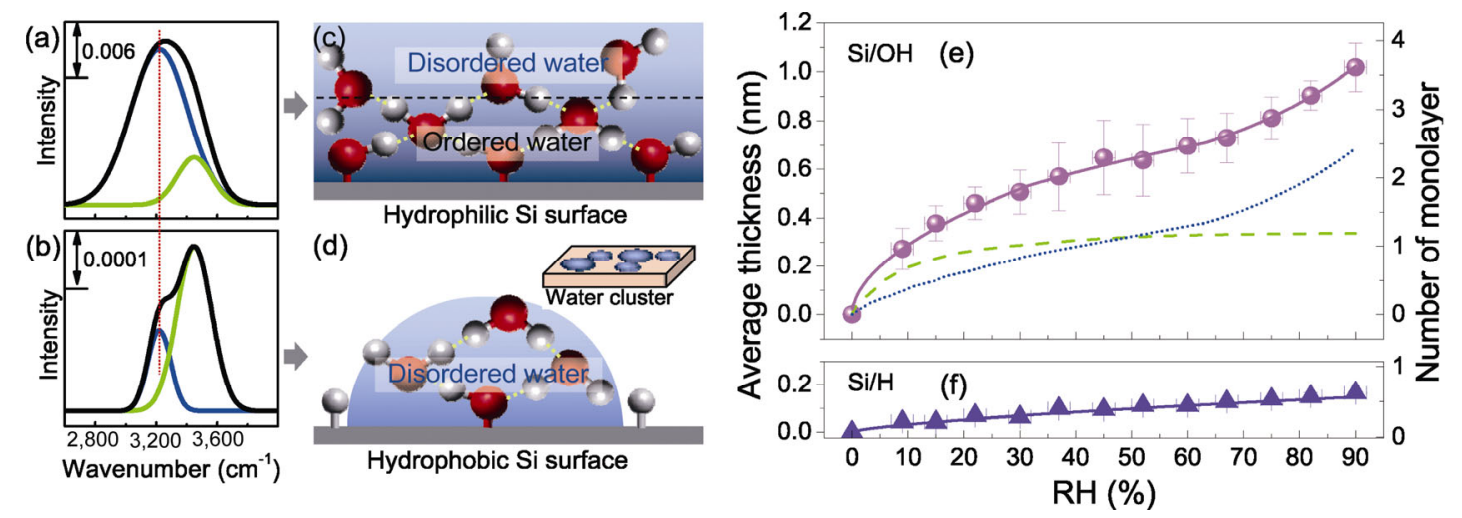

Fig. 4 Schematic of ATR-IR spectra of O-H stretching region of water adsorbed on (a) hydrophilic hydroxyl-terminated silicon $(\mathrm{Si} / \mathrm{OH})$ surface; (b) hydrophobic hydrogen-terminated silicon $(\mathrm{Si} / \mathrm{H})$ surface; (c) $\mathrm{Si}-\mathrm{OH}$ surface (showing corresponding adsorbed water structure); and (d) $\mathrm{Si}-\mathrm{H}$ surface in humid air. Inset in (d) shows schematic of clusters of water molecules on hydrophobic $\mathrm{Si}-\mathrm{H}$ surface; (e, f) illustrate adsorption isotherms of adsorbed water on hydrophilic $\mathrm{Si}-\mathrm{OH}$ and hydrophobic $\mathrm{Si}-\mathrm{H}$ surfaces, respectively. Solid line is drawn as guide. Green dashed and blue dotted lines represent the thicknesses of disordered and ordered water, respectively. Number of layers is calculated by dividing average thickness with average diameter of water molecule ( $2.82 \AA)$. Reproduced with permission from Ref. [67], (C) American Chemical Society 2018.

range and has a lower relative intensity than bulk liquid water (Fig. 4(b)). This indicates that no ice-like water exists on the hydrophobic $\mathrm{Si} / \mathrm{H}$ surface. With the increase in $\mathrm{RH}$, the adsorbed water on the hydrophilic $\mathrm{Si} / \mathrm{OH}$ surface, which involves both ordered and disordered structures, finally grows to practically four layers (Fig. 4(e)). In contrast, only the disordered water with an average thickness less than that of the monolayer forms on the hydrophobic $\mathrm{Si} / \mathrm{H}$ surface even at the near-saturation RH (Fig. 4(f)). This indicates the possible formation of a water cluster structure near the defect sites (upper-right in Fig. 4(d)) [68]. Recently, Chen et al. [69] found that the gel-like three-dimensional (3D) structure on the Si surface could further enhance the condensation of both ordered and disordered water. It is intriguing that the Si surface with a gel-like structure uptakes three times the amount of adsorbed water on the $\mathrm{Si} /$ $\mathrm{OH}$ surface although the contact angle of the latter is considerably smaller (more hydrophilic). Similarly, Baumgartner et al. [70] observed the formation of ordered water on mesoporous silica films, and its amount was dependent on the size of the pores.

In summary, both the spectroscopic characterizations and computational simulations confirm that the additional interaction with the solid surface may result in the adsorption of well bond- ordered (ice-like) water. The increase in water vapor pressure at low $\mathrm{RH}$ values and hydrophilization or formation of hydrophilic "hair-like" structures on the solid surface can facilitate the growth of ice-like water. The condensation of ice-like water does not only increase the interfacial adhesion and friction forces; it also causes more severe water-associated tribochemical wear, which is reviewed in the succeeding sections. The foregoing functions differ from the role of lubrication provided by the liquid-like water forming on the hydrophobic surface or on the hydrophilic surface at high $\mathrm{RH}$ values.

\section{Capillary-related adhesion depending on water configuration}

Capillarity is a general phenomenon that occurs between two contacting or near-contacting surfaces in a vapor environment. In such a case, the capillary force of the meniscus has a significant contribution to the interfacial adhesion especially in the microscale/ nanoscale asperity contact. In this Section, the effects of capillarity on the interfacial adhesion are reviewed. It is based on the development of the capillary-related adhesion model from the Young and Laplace model at the macroscale/mesoscale level to the Xiao and Qian model at the microscale/nanoscale level. It is further extended to the Kim-Chen-Qian model, 
considering the contribution of the ice-like water formed on the hydrophilic solid surface and enhanced by the hydrophilic "hair-like" surface structure.

\subsection{Capillary-related adhesion model at nanoscale}

It is widely regarded that capillarity is time and temperature-dependent, and the capillarity bridge grows until the thermodynamic equilibrium is established. Szoszkiewicz and Riedo [71] deduced that the time of meniscus nucleation between two hydrophilic contacting surfaces ranged from 0.7 to $4.2 \mathrm{~ms}$ in humid air with $40 \% \mathrm{RH}$ as the temperature decreased from 332 to $299 \mathrm{~K}$. This conclusion was based on the transition of the velocitydependent microscale/nanoscale friction from a logarithmic velocity-dependent friction to one that is constant. Physically, capillary condensation is considered as a thermally activated fIrst-order gas-liquid phase transition. They estimated the energy barrier of a capillary bridge nucleation to be approximately $7.8 \times 10^{-20} \mathrm{~J}$ based on Arrhenius law.

The quantitative study of capillarity at a thermodynamic equilibrium state can be traced back to the mid-19 $9^{\text {th }}$ century and the work of McFarlane and Tabor [72]. For a single sphere-on-plane contact, the capillary force $\left(F_{\mathrm{c}}\right)$ can be estimated by

$$
F_{\mathrm{c}}=4 \pi \gamma\left(\cos \theta_{1}+\cos \theta_{2}\right)
$$

where $\gamma$ is the water surface tension. The model of Young and Laplace functions at the macroscale/ mesoscale level based on three main assumptions (Figs. 5(a) and 5(b)): (i) the meniscus radius $\left(r_{\mathrm{L}}\right)$ is considerably smaller than the radius $(R)$ of the sphere; (ii) the distance between the sphere and flat surface $(a)$ is considerably smaller than $r_{\mathrm{L}}$; (iii) the Kelvin radius of the meniscus $\left(r_{\mathrm{K}}\right)$ is considerably smaller than $r_{\mathrm{L}}$. However, the above model fails to predict the interfacial adhesion at the microscale/ nanoscale level because $r_{\mathrm{K}}$ is considerable with $r_{\mathrm{L}}$, which is in turn considerable with $R$ [73].

With the development of new technologies, such as the atomic force microscope (AFM) and surface force apparatus, the sphere-on-plane contact size in the capillary study shrinks to the microscale or even nanoscale level. Using the AFM, Xiao and Qian [74] detected that the RH had no effect on the hydrophobic OTE/ $\mathrm{SiO}_{2}$ surface (OTE, N-octadecyltrimethoxysilane self-assembled monolayer film). In contrast, the complex dependence of adhesion on $\mathrm{RH}$ was observed on the hydrophilic $\mathrm{SiO}_{2}$ surface fully covered by hydroxyl groups (i.e., $\mathrm{SiO}_{x} / \mathrm{OH}$ ). The RH-dependent adhesion behaviors on hydrophobic and hydrophilic solid surfaces can be explained by the different evolutions of water adsorption. The adsorbed water layer on a hydrophobic surface is extremely thin even at a nearly saturated water vapor pressure; its structure does not change with $\mathrm{RH}$ (Fig. 4) and the adhesion force is small, exhibiting independence on $\mathrm{RH}$ [67]. The growth of the adsorbed water around the annulus of the contact area on a hydrophilic surface changes the capillary interaction and the related adhesion behaviors depending on RH. However, the Young and Laplace model cannot explain the fact that the adhesion force on the $\mathrm{SiO}_{x} / \mathrm{OH}$ surface increases to a maximum and then decreases as the RH increases (Fig. 5(c)). The same RH-dependent single-asperity contact was also reported by other published articles in Refs. [75-77]. To explain the complex RH-dependent interfacial adhesion behaviors, Xiao and Qian [74] built the first capillary-related adhesion model utilized at the microscale/nanoscale level, considering the contacting asperity size and meniscus shape.

In general, the adhesion force at the asperity contact interface consists of the capillary force $\left(F_{\text {cap }}\right)$, van der Waals force $\left(F_{\mathrm{vdW}}\right)$, electrostatic force, and chemical bonding force. Compared with the total adhesion, the electrostatic and chemical bonding forces are limited because there are no net charges and surface bond saturation. The capillary force is the sum of two components: surface tension $\left(F_{s}\right)$ and pressure difference $\left(F_{\mathrm{p}}\right.$, between the outside and inside of the meniscus) caused by the curvature. Based on the sphere-on-plane contact geometry, Xiao and Qian [74] established the relationship between the capillary force and filling angle $(\phi)$ of the meniscus (Fig. 5(a)).

$$
\begin{aligned}
F_{\text {cap }}=F_{\mathrm{s}}+F_{\mathrm{p}}= & 2 \pi \gamma R \sin \phi \sin \left(\theta_{1}+\phi\right) \\
& +\pi \gamma R\left(-\sin \phi+\frac{\cos \left(\theta_{1}+\phi\right)+\cos \theta_{2}}{\frac{a}{R}+1-\cos \phi} \sin ^{2} \phi\right)
\end{aligned}
$$


In Eq. (2), the $\phi$ is determined by the Kelvin equation at a thermodynamic equilibrium state, where $V_{0}$ is the volume of water molecules [78].

$$
\frac{k T}{\gamma V_{0}} \ln \mathrm{RH}=\left(\frac{1}{r_{\mathrm{L}}}-\frac{1}{r_{\mathrm{K}}}\right)=\frac{1}{R \sin \phi}+\frac{\cos \left(\theta_{1}+\phi\right)+\cos \left(\theta_{2}\right)}{a+R(1-\cos \phi)}
$$

The water condensation on the sphere-on-plane contact not only affects the capillary force but also the van der Waals force. According to the basic formula of van der Waals force calculation, $F_{\mathrm{vdW}}=$ $H R / 6 a^{2}$ (where $A$ is Hamaker constant depending on the medium at the contact interface), and $F_{\mathrm{vdW}}^{\mathrm{RH}}$ at various $\mathrm{RH}$ values is approximated between the values in dry air $\left(F_{\mathrm{vdW}}^{\mathrm{dry}}\right)$ and pure water $\left(F_{\mathrm{vdW}}^{\text {water }}\right)$ $[79,80]$.

$$
\begin{aligned}
F_{\mathrm{vdW}}^{\mathrm{RH}}= & F_{\mathrm{vdW}}^{\mathrm{dry}}\left\{\frac{1}{[1+R(1-\cos \phi) / a]^{2}}\right\} \\
& +F_{\mathrm{vdW}}^{\mathrm{water}}\left\{1-\frac{1}{[1+R(1-\cos \phi) / a]^{2}}\right\}
\end{aligned}
$$

The results calculated using Eqs. (2)-(4) show that the capillary force increases at a low $\mathrm{RH}$ range following a decrease at a high RH (III in Fig. 5(d)); the van der Waals force monotonously drops continuously as the $\mathrm{RH}$ increases from $0 \%$ to saturation (IV in Fig. 5(d)). The total adhesion calculated from $F_{\text {cap }}+F_{\mathrm{vdW}}(\mathrm{V}$ in Fig. 5(d)) similarly varies as a function of $\mathrm{RH}$ compared with the experimental data on the hydrophilic $\mathrm{SiO}_{2} / \mathrm{OH}$ surface (Fig. 5(c)): both increase at low RH values and decrease at high $\mathrm{RH}$ values.

\subsection{Capillary-related adhesion model considering ice-like water}

The model built by Xiao and Qian [74] can approximately predict the trend of adhesion variation with $\mathrm{RH}$ for a single-asperity contact; however, the fitted data do not precisely match the experimental results (Fig. 5(d)). One possible reason is the omission of the influence of the strongly hydrogen-bonded ice-like water in the meniscus. Compared with the bulk liquid water, the ice-like adsorbed water has surface energy that is approximately two times higher $\left(\gamma_{\text {ice }}=\right.$ $\sim 103.3 \mathrm{ergs} / \mathrm{cm}^{2}$ ) [81] and a considerably smaller relaxation time (six to eight orders of magnitude slower) [82]. Asay and Kim [83] demonstrated that the magnitude of the RH-dependent adhesion of $\mathrm{SiO}_{\times} / \mathrm{OH}$ and $\mathrm{Si}$ single-asperity contact interface was extremely underestimated by considering only the contributions of capillary and van der Waals forces; the contribution of the ice-like water bridge must also be considered. The force required to rupture the ice-like water bridge $\left(F_{\text {ice }}\right)$ can be approximated as $F_{\text {ice }}=\mathrm{d} W / \mathrm{d} z$, where $\mathrm{d} W=$ $2 \gamma_{\text {ice }} d A_{\text {ice }}\left(A_{\text {ice }}\right.$ : area of ice-like meniscus $)$ and $\mathrm{d} z=$ $2^{1 / 6} \delta$ (Lennard-Jones parameter: $\delta=\sim 3.15 \AA$ ) [84]. Based on the sphere-on-plane geometry, $F_{\text {ice }}$ is a function of the ice-like water layer thickness $\left(h_{\text {ice }}\right)$. The entire adsorbed water layer $(h)$ can be expressed as

$$
F_{\text {ice }}=\frac{2 \pi \gamma_{\text {ice }}(h+2 R)\left(2 h_{\text {ice }}-h\right)}{2^{1 / 6} \delta}
$$

Thereafter, Asay and Kim [83] extended the Xiao and Qian model considering the contribution of ice-like water bridge to the interfacial adhesion, especially between two hydrophilic contact surfaces. This aids in understanding the influence of structure, thickness, and viscoelastic behavior of condensed water meniscus on the adhesion force at a nano-asperity contact.

\subsection{Capillary-related adhesion model considering interfacial water configuration}

Recently, the group of Chen and Qian [85] developed a comprehensive model involving the roles of capillary force and van der Waals force as well as the dynamic contribution of the breaking of the ice-like meniscus depending on the chemistry and physical structures of the solid surface. They controlled the surface wettability of Si by storing a fully hydrogen-terminated $\mathrm{Si}(\mathrm{Si} / \mathrm{H})$ in liquid alcohol $\left(\mathrm{Si}_{\text {alcohol }}\right), 40 \% \mathrm{RH}$ air $\left(\mathrm{Si}_{\text {air }}\right)$, and water $\left(S i_{\text {water }}\right)$ with different aging times. The water contact angle of pristine $\mathrm{Si} / \mathrm{H}$ is approximately $85^{\circ}$. After aging for up to $28 \mathrm{~d}$, the contact angle gradually reduces to $\sim 65^{\circ}$ for the Sialcohol surface, where only a liquid-like water cluster condenses around the hydrophilic defect sites (I in Fig. 6). The storage in humid air produces an oxide layer terminated by hydroxyl groups, resulting in the 

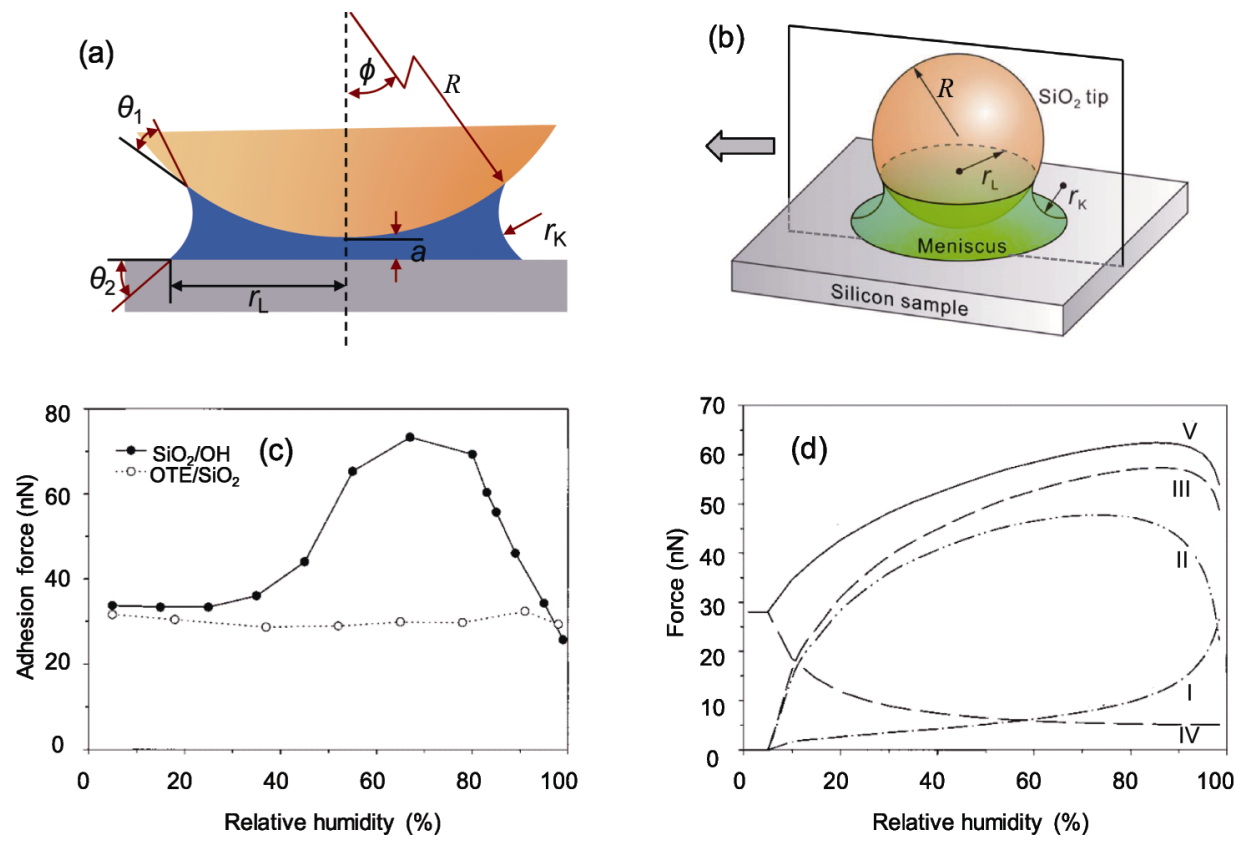

Fig. 5 (a, b) Geometry of meniscus condensed on single-asperity contact interface; $R$ is sphere radius; is filling angle; $r_{\mathrm{K}}$ is Kelvin radius of meniscus; $r_{\mathrm{L}}$ is meniscus radius; $a$ is minimum separation at sphere-plane interface; $\theta_{1}$ and $\theta_{2}$ are contact angles of sphere and substrate, respectively; (c) adhesion forces as function of $\mathrm{RH}$ on relatively hydrophilic $\mathrm{SiO}_{2}$ surface and hydrophobic OTE/ $\mathrm{SiO}_{2}$ surface obtained in AFM tests; (d) theoretical calculation results on contributions to adhesion force from (I) surface tension force, (II) capillary pressure force, (III) total capillary force, (IV) van der Waals force, and (V) adhesion force. Reproduced with permission from Ref. [74], (C) American Chemical Society 2000.

decrease in contact angle to $\sim 40^{\circ}$ for $\mathrm{Si}_{\text {air }}$ and the condensation of ice-like water (II). After being aged in water, a loosely cross-linked gel-like structure is formed on the Si surface. Thereafter, the water uptake of the $\mathrm{Si}_{\text {water }}$ surface induces a considerably thicker ice-like water layer (III) than the $\mathrm{SiO}_{x} / \mathrm{OH}$ surface although it is more hydrophobic $\left(\theta \geqslant 15^{\circ}\right)$ [69]. This dynamics of the interfacial water configuration indicates that the contribution of the breakage of the ice-like meniscus to adhesion must be dynamic. The adhesion force $\left(F_{\mathrm{a}}\right)$ determined by the filling angle of ice-like meniscus ( $\phi_{\text {ice }}$ ) can be written as [85] follows:

$$
\begin{aligned}
F_{\mathrm{a}}= & F_{\mathrm{vdW}}+F_{\mathrm{c}}+\beta F_{\text {ice }}=F_{\mathrm{vdW}}\left(\phi_{\text {ice }}\right)+F_{\mathrm{c}}\left(\phi_{\text {ice }}\right) \\
& +\beta \frac{2 \pi \gamma_{\text {ice }}\left(R \sin \phi_{\text {ice }}\right)^{2}}{2^{1 / 6} \sigma}
\end{aligned}
$$

where $\beta$ is a parameter that can vary depending on the interfacial water configuration. For a plane surface, the ice-like water gradually grows with surface hydrophilization, corresponding to $0 \leqslant \beta \leqslant 1$. For a gel-like structure-covered $\mathrm{Si}$ surface, a considerably thicker ice-like water layer is formed because of the water uptake; thus, $\beta$ should be larger than 1. Although the exact nature or dynamics of the physical process requires further study, the theoretical curve constructed with $\beta=0-3$ exhibits a reasonable agreement with all the data on adhesion when the water contact angle of the Si surface ranges from $\sim 83^{\circ}$ to $\sim 15^{\circ}$ (rhodopsin solid line in Fig. 6). The capillary and van der Waals force interactions (green dashed line in Fig. 6) or their combination with the fixed ice-like water contribution (blue dashed line in Fig. 6) cannot fully match the experimental results influenced by both surface wettability and physical structure [85].

In summary, the condensation of the meniscus at the interface has a complex influence on the capillary-related adhesion behavior. The capillarity is enhanced with the initial growth of interfacial water but weakens upon extreme water adsorption because of variations in surface tension and capillary pressure forces. In contrast, the role of interfacial water structure in adhesion should be considered. The growth of ice-like water significantly contributes to the increase in adhesion force as the water vapor pressure increases, or with the hydrophilization of the surface and formation of 


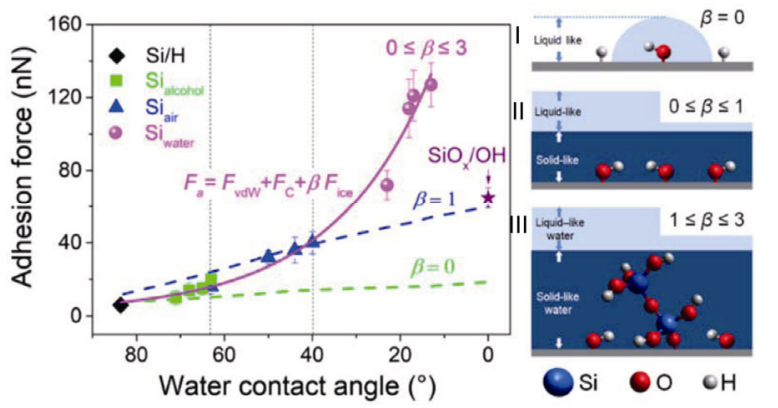

Fig. 6 Adhesion force vs. water contact angle of $\mathrm{Si}_{3} \mathrm{~N}_{4} /$ silicon pairs simulated with contributions of van der Waals force $\left(F_{\mathrm{vdW}}\right)$, capillary force of liquid meniscus $\left(F_{\mathrm{c}}\right)$, and force necessary to break strongly hydrogen-bonded water network $\left(F_{\text {ice }}\right)$. Bottom green and middle blue dashed lines represent $F_{\mathrm{vdW}}+F_{\mathrm{c}}$ and $F_{\mathrm{vdW}}+F_{\mathrm{c}}+F_{\text {ice }}$, respectively. The rhodopsin solid line represents $F_{\mathrm{vdW}}+F_{\mathrm{c}}+\beta F_{\text {ice }}$, where $0 \leqslant$ $\beta \leqslant 3$ depending on water adsorption is related to chemistry and structure of oxidized surface layer, as shown in insets on right. Reproduced with permission from Ref. [85], (C) American Chemical Society 2020.

a hydrophilic "hair-like" surficial structure.

\section{Effects of interfacial water structure on friction}

Based on the well-known Amontons relationship between friction force $\left(F_{\mathrm{t}}\right)$ and normal load $\left(F_{\mathrm{n}}\right)$, $F_{\mathrm{t}}=\mu\left(F_{\mathrm{n}}+F_{\mathrm{a}}\right)[86]$, the change in friction because of water condensation has two origins: the variations in adhesion force and friction coefficient $(\mu)$. The solid adsorption-solid adhesion model described in Eqs. (1)-(6) presents the effects of temperature and relative humidity on the capillary-related adhesion. However, it does not extend to other important parameters (e.g., velocity and contact time) in sliding friction. This section presents the meniscus condensation, which mainly depends on the velocity and RH. Its effect on the capillaryrelated friction is reviewed based on the developments of the multi-asperity and single-asperity meniscus models, considering the evolution of interfacial water structure.

\subsection{Multi-asperity meniscus model}

In the previous paper, it has been reported that the friction at the microscale/nanoscale level is extremely velocity-dependent [87-89], and the cases occurring on the hydrophilic surface under a humid condition are considerably related to meniscus reconfiguration $[11,90]$. A multi-asperity meniscus model established by Bocquet et al. [11] and further developed by Riedo et al. [91] suggest that the dependence of capillary-related friction on the contact time (or velocity) and the $\mathrm{RH}$ is significantly related to the variation in the number of meniscus that forms between the contacting and near-contacting asperities. With the increase in $\mathrm{RH}$ or decrease in velocity, the quantity of meniscus logarithmically increases with the contact time or as a function of $\mathrm{RH}$, resulting in the increase in capillary force and related friction force.

In the multi-asperity meniscus model, for each contacting or near-contacting asperity shown in Fig. 7(a), one gap of height $h$ defines the volume of a potential meniscus: $V=h A$, where $A$ is the bridge cross-section. Based on the assumption of a meniscus with a constant cross-sectional area, the condensation of such a meniscus costs a threshold free energy, $\Delta E(h)=k_{\mathrm{B}} T \ln (1 / \mathrm{RH}) h A / v_{0}$. Assuming that there is an activation process, the time necessary to form a bridge with height $h$ is $t(h)=t_{\mathrm{a}} \exp \left[\Delta E(h) / k_{\mathrm{B}} T\right]$, where $t_{\mathrm{a}}$ is the condensation time of a liquid monolayer. Thereafter, the maximum height $\left(h_{\max }\right)$ of the meniscus at a given time, $t$ (or velocity, $v)$, and $\mathrm{RH}$ can be estimated as $h_{\max }=$ $\ln \left(t / t_{\mathrm{a}}\right)[\ln (1 / \mathrm{RH}) A \rho]^{-1}=\ln \left(v_{\mathrm{a}} / v\right)[\ln (1 / \mathrm{RH}) A \rho]^{-1}$, where $\rho$ is the molecular density of the liquid (molecules $\left./ \mathrm{m}^{3}\right) ; v_{\mathrm{a}}$ is defined as $d / t_{\mathrm{a}}$ ( $d$ is the contact region diameter). This means that only two asperities with a gap less than $h_{\max }$ can form a meniscus. Thus, because of roughness, the fraction $f(v)$ of the total number of meniscus is approximated as $f(v)=h_{\max }(v) / \lambda$, where $\lambda$ is the full width of the interstitial height distribution $[11,91]$. Considering that the capillary force is reduced by the factor $f(v)$ from the perfectly smooth case $\left(F_{\text {cap }}\right)$, the total friction force that depends on the velocity and $\mathrm{RH}$ can be written as follows [91]:

$$
\begin{gathered}
F_{t} \propto \mu\left(F_{N}+F_{\text {ss }}\right)+\mu F_{\text {cap }} f(v)=\mu\left(F_{N}+F_{\text {ss }}\right)+\mu F_{\text {cap }} \times \\
{\left[\frac{1}{\lambda \rho A \ln (1 / \mathrm{RH})}\right] \ln \left(\frac{v_{a}}{v}\right)}
\end{gathered}
$$


Here, the adhesion force is $F_{\mathrm{a}}=F_{\mathrm{ss}}+F_{\text {cap }}$, where $F_{\mathrm{ss}}$ is the direct adhesion of two contacting solids in liquid [71]. Using the multi-asperity meniscus model in Eq. (7), Riedo et al. [91] successfully predicted the velocity and $\mathrm{RH}$-dependent friction on the partially hydrophilic high-temperature deposited CrN (HT-CrN) and the native oxidecovered Si (100) surfaces slid against the Si AFM tip. The friction forces decrease logarithmically with the increase in velocity at RHs values of $1 \%$ and $34 \%$ on the HT-CrN surface (Fig. $7(\mathrm{~b})$ ) and then increase linearly with $1 / \ln (1 / \mathrm{RH})$ (or $1 / \ln$ $\left.\left(P_{\mathrm{S}} / P\right)\right)$ on the HT-CrN and Si surfaces (Fig. 7(c)).

The multi-asperity meniscus model for the thermally activated nucleation of water bridges between two contacting or near-contacting asperities has been successfully used to reproduce the velocity and RH dependencies of friction force. However, the applications of this model are largely limited to the prediction of friction behaviors because of several reasons. First, the topographies of the contacting surfaces are simplified as a constant cross-section of the meniscus of each single-asperity contact and uniform roughness of the contacting surfaces in this model (Fig. 7(a)). In reality, the shape, height, and distribution of the asperities
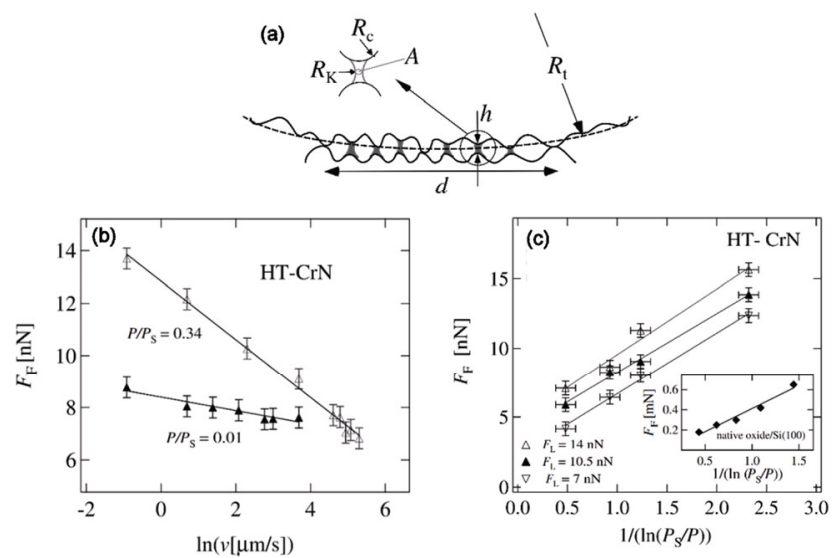

Fig. 7 (a) Friction behaviors at microscale/nanoscale level explained by a multi-asperity contact model; (b) schematic of multi-asperity contact with condensation of water bridge; (c) friction force as a function of sliding velocity, $\ln [v(\mu \mathrm{m} / \mathrm{s})]$ and relative humidity, $1 / \ln \left(P_{\mathrm{S}} / P\right)$ or $1 / \ln (1 / \mathrm{RH})$, on hydrophilic HT-CrN surface. Inset in (c) shows friction force vs. $1 / \ln \left(P_{\mathrm{S}} / P\right)$ on native oxide-covered $\mathrm{Si}(100)$ surface. Reproduced with permission from Ref. [91], (C) American Physical Society 2002. on a rough surface are discrete. All of these features have been proved to determine the capillary-related friction force because of the different water adsorption behaviors [92-95]. Second, the use of this model is limited to the case where the water condensation enhances the capillarity. This model cannot predict the fact that the growth of liquidlike water on the hydrophilic surface at high $\mathrm{RH}$ values suppresses the capillary effect and related friction force. Third, a single-asperity contact can be simulated between the interface of a sharp AFM tip with a nanometer radius and an atomic substrate (graphene/graphite and Si surface with sub-nanometer roughness). The multi-asperity meniscus model fails to explain the corresponding friction behavior depending on water condensation.

\subsection{Single-asperity meniscus model: Friction enhanced by ice-like water}

When the roughness of contact surfaces is minimized to the sub-nanometer or nanometer scale, the sliding interface should be modeled with a single-asperity contact if the elastic deformation of the solid at a given load is larger than the topographic features of the initial surface before the contact $[96,97]$. Under this condition, the multi-asperity meniscus model is inapplicable, and the role of the water structure (proven to be significant in adhesion (Section 2)) at the contact interface must be considered.

Chen et al. [98] studied the friction behaviors at a single-asperity contact on a silicon surface with sub-nanometer roughness using the AFM and $\mathrm{SiO}_{2}$ microspherical tip; they also observed a similar velocity-dependent and $\mathrm{RH}$-dependent friction reported in Ref. [91]. As the velocity increases, the friction force of the $\mathrm{SiO}_{2} / \mathrm{Si}$ single-asperity contact exhibits $\mathrm{a}-\ln (v)$ dependence in the low-velocity regime. It levels off at a critical velocity $\left(v_{a}\right)$, which is dependent on the $\mathrm{RH}$. As the $\mathrm{RH}$ increases, the friction force exhibits dependence on $1 / \ln (1 / \mathrm{RH})$ at a low- $\mathrm{RH}$ regime $(\mathrm{RH}<50 \%)$ and levels off at the high- $\mathrm{RH}$ regime $(\mathrm{RH} \geq 50 \%)$. Although experimental measurements are impossible because of size limitation, the volume of the meniscus $(V)$ at the sliding interface can be estimated as $V=$ $\int_{0}^{h_{\max }} A(h) \mathrm{d} h=\ln \left(v_{\mathrm{a}} / v\right)[\ln (1 / \mathrm{RH}) \rho]^{-1}$. Based on the 
same dependence of the meniscus volume on the velocity and $\mathrm{RH}$ in theory and friction in experiments, Chen et al. [98] found that the capillary-related friction force varies linearly with the meniscus volume (Fig. 8(a)) when the interfacial water is dominated by the ice-like structure at $\mathrm{RH}<50 \%$ (Fig. 4(e)).

$$
\begin{aligned}
F_{\mathrm{t}} & =\text { intercept }+\eta V \\
& =\text { intercept }+\eta \ln \left(v_{\mathrm{a}} / v\right)[\ln (1 / \mathrm{RH}) \rho]^{-1}
\end{aligned}
$$

Here, the slope $(\eta)$ of the fitting line physically means the force required to drag a unit volume of meniscus. However, the dependence of the meniscus on volume declines when $\mathrm{RH} \geq 50 \%$ (Fig. 8(b)). Under this humidity, the ice-like water stops growing and the liquid-like water becomes dominant (Fig. 4(e)). This implies that the contribution of liquid-like water to friction is considerably limited compared to that of ice-like water. It is presumed that the surfaces terminated by the hydrophilic groups containing the $\mathrm{H}$ acceptor and donor moieties can form strongly H-bonded networks (ice-like water) [99]. Furthermore, the condensation of more ice-like water enhances the domains of glassy H-bonded networks, which are more difficult to disrupt, thereby resulting in greater friction.

\subsection{Single-asperity contact at high RH: Friction suppressed by liquid-like interfacial water}

Different from the friction behaviors in the low$\mathrm{RH}$ range, it is found that the single-asperity friction at the hydrophilic sliding interface decreases when

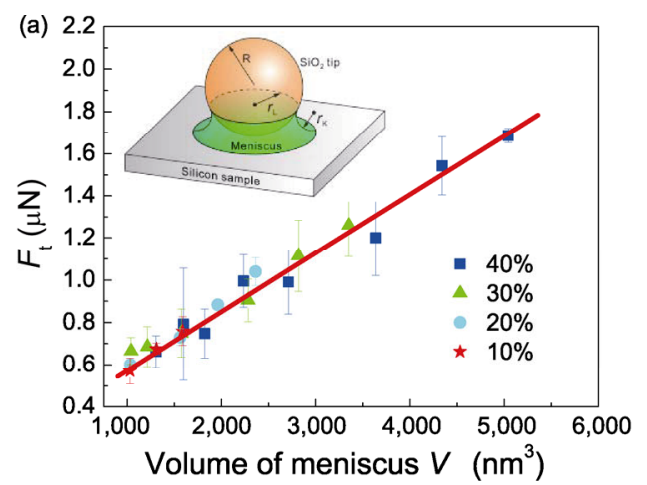

$\mathrm{RH}>70 \%$. The non-monotonic variation of the $\mathrm{RH}$-dependent friction has been observed in broad sliding systems, such as $\mathrm{SiO}_{2} /$ mica [100], Si/CrN [91, $\mathrm{SiO}_{2} / \mathrm{Si}[37,38,101], \mathrm{Si} / \mathrm{ZnO}$ [102], and taC/HOPG [12] interfaces. The adhesion force described in Section 2.1 also exhibits a similar nonmonotonic behavior [74-78], which is mainly attributed to the evolution of the adsorbed water configuration $[83,85]$. For the $\mathrm{SiO}_{2} / \mathrm{Si}$ single-asperity contact interface, it is clear that the condensation of ice-like meniscus at low RH values $(<40 \%-80 \%$; the exact $\mathrm{RH}$ depends on the solid surface chemistry and physical structure) corresponds to increases in adhesion and friction. Conversely, the fast growth of the liquid-like meniscus at high $\mathrm{RH}$ values corresponds to the decreases in adhesion and friction [61, 67, 83]. Therefore, it can be deduced that a part of the liquid-like water in the interfacial meniscus can act as a lubricant.

Recently, Hasz et al. [12], using the AFM and Grand Canonical Monte Carlo (GCMC) simulations, investigated the stick-slip friction of tetrahedral amorphous carbon (ta-C) AFM tip sliding against a highly oriented pyrolytic graphite (HOPG) at different RH values (Fig. 9(a)). They observed the non-monotonic change in the RH-dependent friction force: An increase at low $\mathrm{RH}$ values $(<60 \%-80 \%)$ and a decrease at high RH values both in the AFM experiments and GCMC calculations (Fig. 9(b)). The analysis of the contact state shown in Fig. 9(c) shows that the solid-solid contact area between the ta-C tip and HOPG interface slightly changes

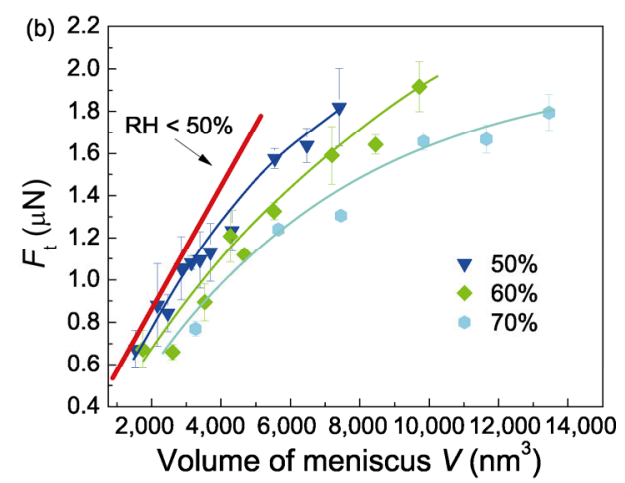

Fig. 8 Friction force vs. $V$ at single-asperity contact interface of $\mathrm{SiO}_{2} / \mathrm{Si}$ pairs with (a) $\mathrm{RH}<50 \%$ and (b) $\mathrm{RH} \geqslant 50 \%$. Inset (a): schematic of meniscus condensed at a single-asperity contact interface under humid conditions. Reproduced with permission from Ref. [38], (C) American Physical Society 2016. Thick red line in (b) is the same trend line found when RH $<$ $50 \%$ in (a). Reproduced with permission from Ref. [98], (C) American Chemical Society 2017. 

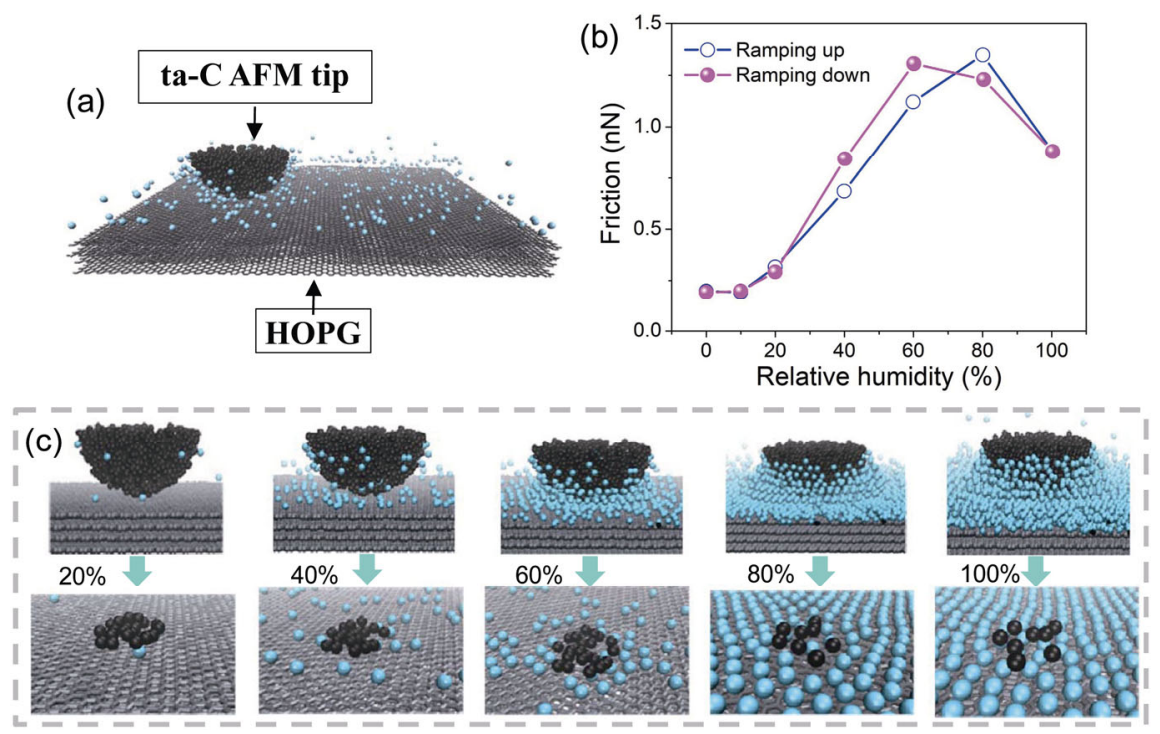

Fig. 9 RH-dependent friction and contact state between a ta-C coated AFM tip and HOPG. (a) Schematic of GCMC simulations of ta-C coated AFM tip sliding on model graphite surface; (b) friction obtained from GCMC simulations; (c) effect of water condensation on contact of amorphous carbon micro-sphere and graphite substrate. Upper: contact models at different RH values in MD simulation. Bottom: change in amount of contacted atoms with increase in RH. Gray ball: carbon atom of HOPG; cyan ball: water molecule; black ball: carbon atom of AFM tip. Reproduced with permission from Ref. [12], (C) American Physical Society 2018.

with the meniscus growth as the $\mathrm{RH}$ increases from $20 \%$ to $60 \%$. However, it exhibits a remarkable decrease after the full monolayer coverage of the adsorbed water forms on the HOPG surface at an RH exceeding $80 \%$ (Fig. 9 (c)). The MD simulations have shown that the ice-like water layer may form on a clean graphene surface [103]. It is highly possible for the liquid-like water to grow as the outermost water layer after the formation of a full monolayer of ice-like water because of the low surface energy of graphene or HOPG. In other words, the growth of a water layer exceeding the monolayer (highly possible to be liquid-like water) increases the separation of ta-C/HOPG, resulting in the decrease in friction force at $\mathrm{RH}>80 \%$. Here, the practically constant solid-solid contact area at low $\mathrm{RH}$ values also indicates that the increase in friction as RH increases is not attributed to the enhancement of the solid-solid contact because of meniscus condensation [104]. It confirms the significant contribution of the growth of strongly $\mathrm{H}$-bonded networks (ice-like water) to the increase in friction at low $\mathrm{RH}$ values.

In summary, the increase in the meniscus number at a multi-asperity contact or growth of ice-like meniscus at a single-asperity contact with the decrease in velocity or increase in $\mathrm{RH}$ causes a higher capillary-related friction. Conversely, the condensation of the liquid-like meniscus may increase the separation between two contact surfaces and reduce the solid contact area. Thereafter, the liquid-like water mainly functions as lubricant. This results in the decrease in the capillary-related friction force. The corresponding results may open a new environment-friendly approach of minimizing the nano-friction in ambient air or water condition (i.e., surface modification to suppress the formation of ice-like water and facilitate the growth of liquidlike water on contacting surfaces).

\section{Role of interfacial water in tribochemical wear}

Water condensation can vary the contact status at the solid interface. It affects not only the interfacial adhesion and friction but also significantly contributes to surface wear. In this section, the effect of interfacial water especially on the tribochemical wear is discussed. The discussion includes the variations in the properties (i.e., wettability and chemistry) of contacting surfaces, environmental conditions (i.e., vapor pressure and temperature), and experimental 
factors (i.e., contact pressure and velocity).

\subsection{Mechanism of tribochemical wear}

Material wear is defined as mechanical wear or tribochemical wear depending on the dominant mechanism of surface damage [105]. Mechanical wear normally involves dislocation, slip, and lattice distortion corresponding to plastic deformation, viscous flow of materials, and even fracture when the applied mechanical stress exceeds the yield limit of related materials [106-108]. Tribochemical wear is attributed to the stress-assisted interfacial bond formation and substrate bond breaking, causing atomic attrition or mechanically facilitated chemical corrosion [109-111]. Different from mechanical wear, the wear activated by tribochemical reaction can occur although the material deformation under impress or shear stress is purely elastic. One typical example is the tribochemical wear of a singlecrystal $\mathrm{Si}$ at the nanoscale level. Jacobs and Carpick [112] were among the earliest groups that employed in situ transmission electron microscopy (TEM) to characterize the wear of Si AFM tip sliding against a diamond-like carbon coating. They directly observed the Si material removal at the atomic level following a perfect crystallographic order in the silicon, which was maintained after the removal of surficial atoms (Figs. 10(a) and 10(b)). Thereafter, Chen et al. [113] investigated the tribochemical wear of a single-crystal $\mathrm{Si}$ that slid against a $\mathrm{SiO}_{2}$ microspherical tip in humid air; they firstly observed a similar phenomenon on the Si substrate.
No dislocations or defects on the silicon lattice subsurface were observed even when it was extremely close to the sliding surface (Figs. 10(c) and $10(\mathrm{~d})$ ). In this study, the applied pressure (1.3 $\mathrm{GPa})$ was considerably less than the yield stress of Si (100) (7 GPa) [114]. Hence, the absence of mechanical damage was reasonable under the conditions of the tribochemical wear experiment.

The development of computational techniques, such as MD simulations and DFT calculations, affords an opportunity to understand the underlying mechanism of the tribochemical reactions at a dynamic state [115]. Chen et al. [116] performed MD simulations with a reactive force field called ReaxFF to simulate a $\mathrm{SiO}_{2}$ nanoparticle sliding against a silicon substrate in the presence of water molecules (Fig. 11 (a)). The MD simulation results confirmed that under the tribochemical wear conditions, few silicon atoms were removed from the Si surface although the substrate elastically deformed under an applied load of $50 \mathrm{nN}$ (Fig. 11(b)) and completely recovered after the load was released (Fig. 11(c)). The removal of Si atoms because of the tribochemical reaction at the contact interface could be presumed as having three stages: (i) generation of surface hydroxyl species through the reaction of surface atoms with water molecules (Fig. 11(d)); (ii) formation of Si-O-Si interfacial bridge bonds via dehydration reaction (Fig. 11(e)); (iii) dissociation of substrate bonds under the action of mechanical shear (Fig. 11(f)), leading to the
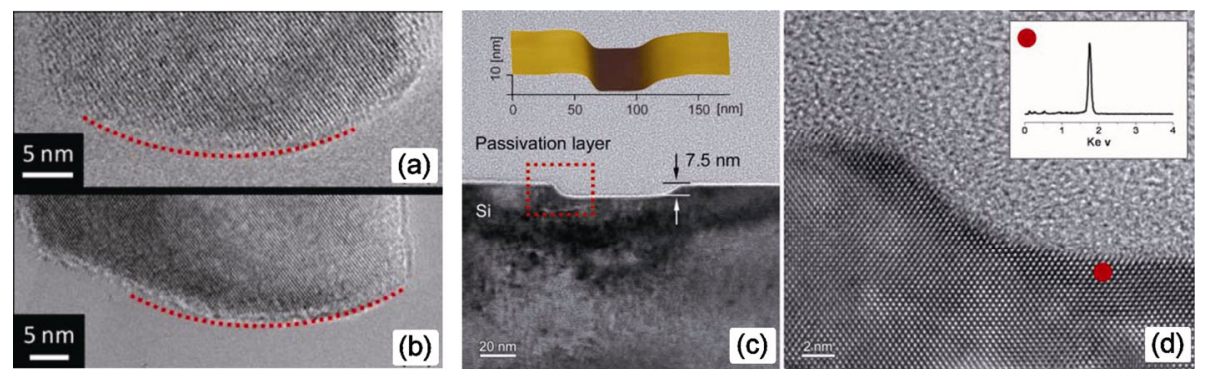

Fig. 10 (a, b) High-resolution TEM images of worn tips without sub-surface damage because of tribochemical wear after removal of material. Reproduced with permission from Ref. [112], (C) Nature 2013. (c) High-resolution TEM images showing an

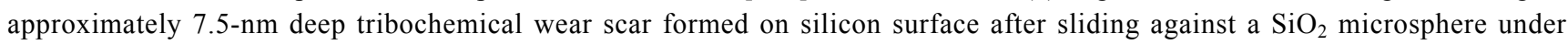
conditions of $P=\sim 1.3 \mathrm{GPa}, \mathrm{RH}=60 \%, v=24 \mu \mathrm{m} / \mathrm{s}$, and $N=100$. Inset shows AFM image of wear scar. (d) Representative lattice-resolved image in worn area marked with box (red dotted line) in (c). EDX spectrum in inset reveals no oxygen is detected in sub-surface of silicon. Reproduced with permission from Ref. [113], C American Chemical Society 2015. 

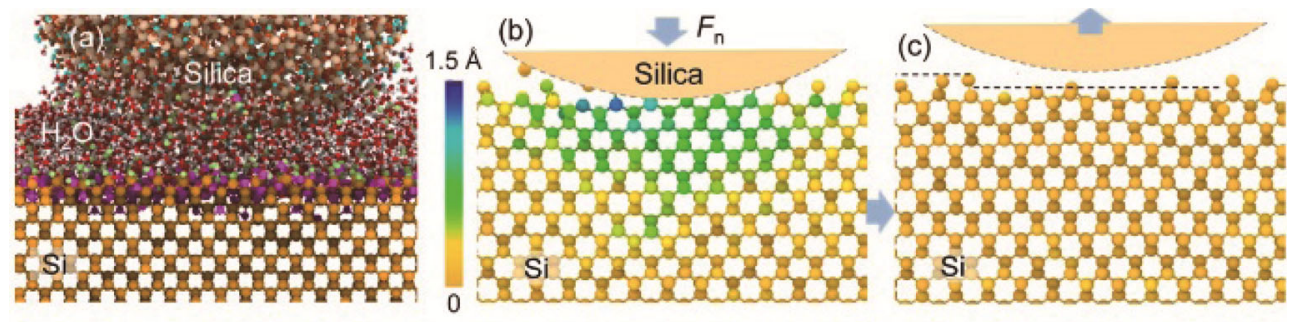

(d) 0 ps

(e) $51 \mathrm{ps}$

(f) $162.5 \mathrm{ps}$

(g) $165 \mathrm{ps}$

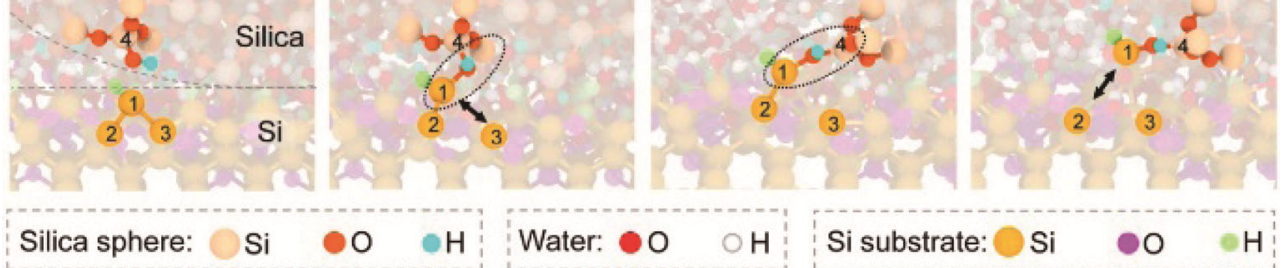

Fig. 11 (a) Tribochemical wear of Si surface against silica nano-sphere in MD simulation; (b) sliding model in MD simulation; (c) deformation of Si substrate under load condition ( $Z$ direction displacement of Si atom under contact pressure is denoted by different colors). (d-g) Removal of $\mathrm{Si}$ atoms and release of substrate deformation after unloading: (d) tribochemical reaction process: initial contact interface reacting with water to form $\mathrm{Si}-\mathrm{H}$ and $\mathrm{Si}-\mathrm{OH}$ groups; (e) formation of interfacial bond bridge between Si substrate and silica surfaces, and breaking of one $\mathrm{Si}-\mathrm{Si}$ bond of Si substrate; (f) tensile stress transferred across interfacial bonding bridges; and $(\mathrm{g})$ fracture of another substrate bond and removal of $\mathrm{Si}$ atom. Reproduced with permission from Ref. [116], (C) Nature 2018.

removal of Si atoms from the substrate (Fig. 11(g)). Furthermore, Wang and Duan [117] used the same simulation method and found that the $\mathrm{Si}$ atom removal was partially attributed to the mechanically induced hydrolysis reaction combined with the interfacial bond formation. Its extent considerably depends on the change in the interfacial shearing action with different amounts of interfacial water molecules.

As a process dominated by a mechanically activated chemical reaction, tribochemical wear cannot be predicted by the empirical Archard wear law, which states that the wear volume is directly proportional to the load and sliding distance [118]. For instance, Jacobs and Carpick [112], Boscoboinik et al. [119], Chen et al. [116, 120], Sheehan [121], and Gotsmann and Lantz [122] investigated the tribochemical wear of nanoscale contacts and indicated that the atomic attrition depending on the contact stress (contact stress is assumed to be proportional to shear stress) follows an Arrhenius-type model (Fig. 12). The volume ( $V$ ) or wear rate $(\tau)$ of the atom removal caused by the tribochemical wear as a function of contact stress $(\sigma)$ can be described as

$$
V(\tau)=b f_{0} \exp \left(-\frac{\Delta U_{\text {act }}}{k_{\mathrm{B}} T}\right) \exp \left(\frac{\sigma \Delta V_{\text {act }}}{k_{\mathrm{B}} T}\right)
$$

where $f_{0}$ is an effective attempt frequency; $b$ is a lattice parameter; $\Delta U_{\text {act }}$ is an activation barrier; $\Delta V_{\text {act }}$ is the critical activation volume; $k_{\mathrm{B}}$ is Boltzmann's constant; $T$ is the absolute temperature. However, both experimental and simulation results indicated that the wear at the nanoscale level shifts from the Arrhenius-type behavior at a low contact stress to an Archard-like behavior at a high contact stress. This indicates the transition of dominant functions from tribochemical reactions to mechanical interactions [123-126].

Tribochemical wear is ubiquitous, and the related mechanisms have been gradually analyzed down to nanoscale and even atomic level [112, 116, 127-129]. In several review papers, the tribochemical wear was solved based on the assumption of chemical reactions among the confined molecules or atoms on the sliding interface [130-132]. Here, the water sensitive tribochemical wear is mainly indicated as depending on the interfacial water configuration. For the two succeeding parts, partly related conclusions can be found in an excellent review paper given by Chen et al. [133]. 

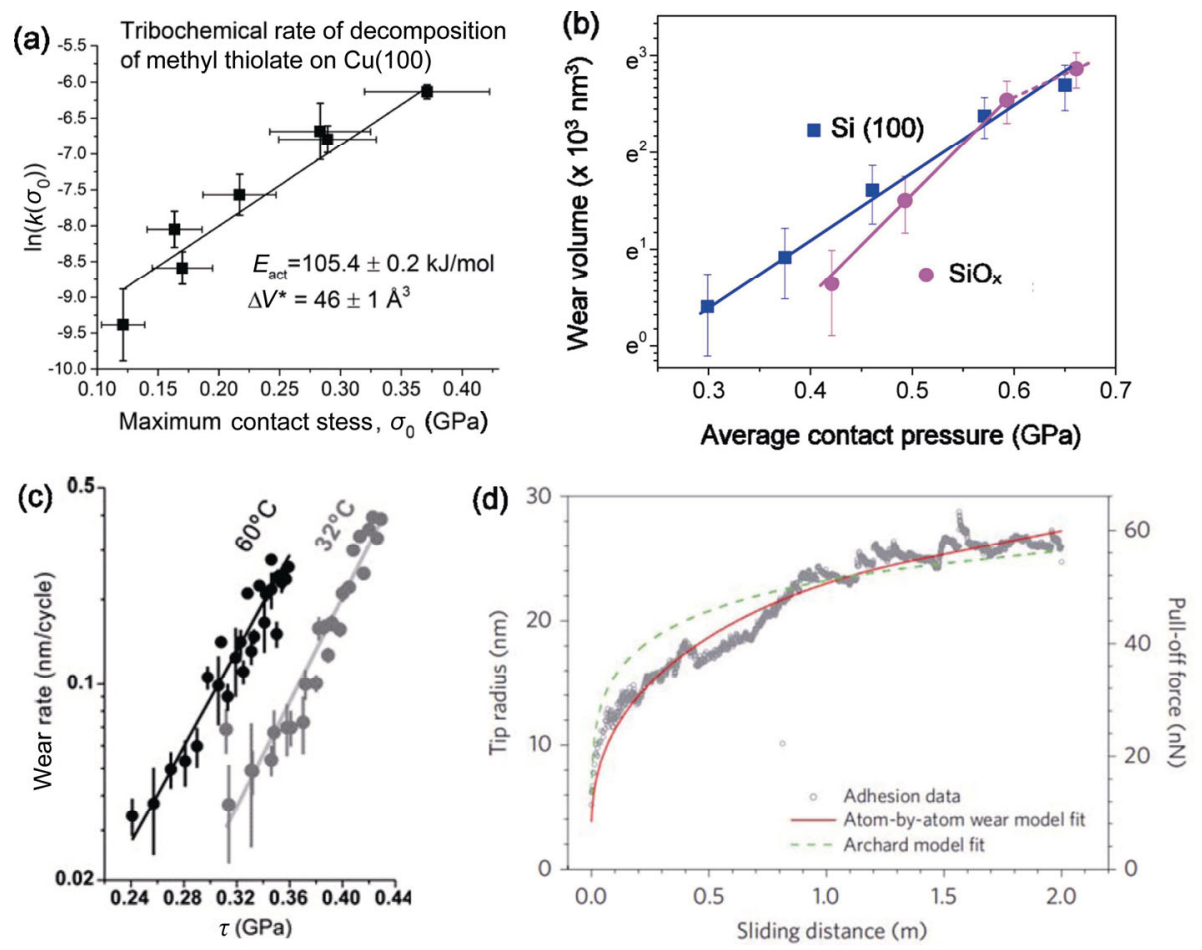

Fig. 12 Experimental results from various tribochemical wear studies. (a) Wear rate (volume) of methyl thiolate on $\mathrm{Cu}(100)$ at 298 K. Reproduced with permission from Ref. [119], (C) Royal Society of Chemistry 2020. (b) Single crystal silicon and native silicon oxide. Reproduced with permission from Ref. [120], (C) Springer 2017. (c) NaCl. Reproduced with permission from Ref. [121], (C) Elsevier B.V. 2005. All exponential increases with stress can be explained using stress-induced tribochemical wear model. (d) Evolution of tip radius as a function of sliding distance can be well fitted by decreasing surface stresses as tip becomes blunter. Reproduced with permission from Ref. [122], (c) American Physical Society 2008.

They summarized the effects of relative humidity on the tribochemical wear of different materials, such as carbon materials (graphite/graphene and carbon films), silicon-based materials, glass, and metals.

Tribochemical wear is ubiquitous, and the related mechanisms have been gradually analyzed down to nanoscale and even atomic level [112, 116. 127-129]. In several review papers, the tribochemical wear was solved based on the assumption of chemical reactions among the confined molecules or atoms on the sliding interface [130-132]. Here, the water sensitive tribochemical wear is mainly indicated as depending on the interfacial water configuration. For the two succeeding parts, partly related conclusions can be found in an excellent review paper given by Chen et al. [133]. They summarized the effects of relative humidity on the tribochemical wear of different materials, such as carbon materials (graphite/ graphene and carbon films), silicon-based materials, glass, and metals.

\subsection{Tribochemical wear facilitated by interfacial ice-like water}

In several studies, the transition of the dominant role in sliding wear from mechanical deformation or damage under dry conditions to tribochemical reaction in humid air or water conditions was demonstrated. The latter can result in the severe wear of many materials, such as silicon (Fig. 13(a)) [134], glass [135-137], GaAs [138], tetragonal zirconia ceramics [139], steel [140], and diamondlike carbon coating [141], although the imposed mechanical stress may be extremely weak. Consider a single crystal $\mathrm{Si}$ as example. When the nanowear was imposed under dry conditions (vacuum, nitrogen, oxygen, or dry air) and under a contact pressure less than its material hardness $(<\sim 11$ GPa), the surface damage after sliding against a $\mathrm{SiO}_{2}$ AFM tip presented the hillock formation (left four images in Fig. 13(a)) [142], which 
mainly consists of a mechanically induced amorphous layer [143, 144]. In contrast, tribochemical reactions occur in moist air, and a remarkable material removal instead of the hillock formation can be observed on the Si surface under the same experimental conditions (Fig. 13(b)) [145-147]. This proves that the presence of water is a necessary condition for the activation of tribochemical reactions at the sliding interface of $\mathrm{Si} / \mathrm{SiO}_{2}$ [148]. Furthermore, the absence of tribochemical wear on the Si surface sliding against an inert diamond AFM tip in humid air (Fig. 13(b)) indicates that the chemistry of the counter-surface also has a crucial function in the tribochemical reaction. The tribochemical wear of Si cannot be caused by the mechanically induced hydrolysis reaction alone [149, 150].

Typically, in the low $\mathrm{RH}$ regime $(<50 \%)$, the tribochemical wear was facilitated by the increase in $\mathrm{RH}$ because of the enhancement of the tribochemical reaction. As mentioned in the Section 1, the thickness and structure of the adsorbed water gradually evolve with $\mathrm{RH}$ especially for a relatively hydrophilic surface. Based on the nanowear studies of $\mathrm{Si}$ sliding against a $\mathrm{SiO}_{2}$ AFM tip as a function of RH, Wang et al. [37] and $\mathrm{Yu}$ et al. [142] found that the change in the rate (volume) of tribochemical wear considerably depended on the configuration of the adsorbed water layer on the Si surface (Fig. 14). In the regime with $\mathrm{RH}<30 \%$, the tribochemical wear of Si sharply increased with the RH when the adsorbed water layer assumed an "ice-like" structure (inset in Fig. 14 (b)). In contrast, the rate of change consid erably decreased when a liquid-like structure started to grow on the solid-like structure in the adsorbed water layer when $\mathrm{RH}>30 \%$. Thereafter, Chen et al. [113] quantified the relationship between the tribochemical wear and adsorbed water configuration on the Si surface. The tribochemical wear rate of $\mathrm{Si}$ is directly proportional to the meniscus volume condensed at the sliding interface (Section 3.2). In other word, both the wear rate of $\mathrm{Si}$ and meniscus volume are proportional to $1 / \ln (1 / \mathrm{RH})$ and decrease logarithmically as the sliding speed increases. A similar relationship between the tribochemical wear rate and sliding speed was also reported in Refs. [151, 152].

Surface wettability that is another important factor to determine water adsorption also has a strong influence on the tribochemical wear. Yu et al. [153] compared the nanowear of Si surfaces with different contact angles at RH of $35 \%-40 \%$. The samples include a fully hydrogen-terminated $\mathrm{Si}$, partially hydroxyl-terminated $\mathrm{Si}$, and fully hydroxyl-covered Si surfaces with contact angles of $<5^{\circ}, 39^{\circ}$, and $83^{\circ}$, respectively. Except for the extremely weak mechanical wear on all the three sample surfaces in vacuum, the severe material removal caused by the tribochemical reactions occurred in humid air under the same conditions. The wear depth gradually increases with the decrease in the water contact angle (surface hydrophilization). At the same $\mathrm{RH}$, as more water molecules adsorb on the more hydrophilic Si surface, the tribochemical reaction is enhanced, facilitating the tribochemical wear of Si. Based (a) $\mathrm{SiO}_{2}$ AFM tip

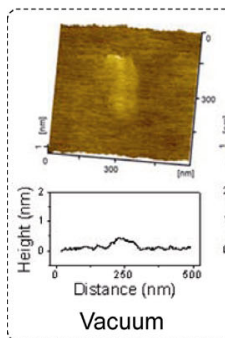

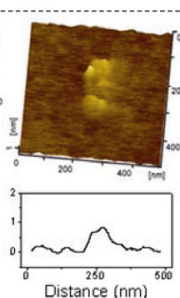

Nitrogen

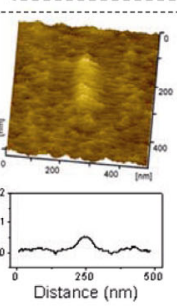

Oxygen

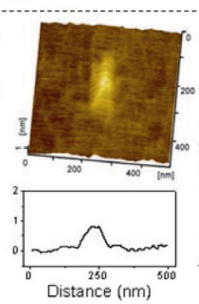

Dry air

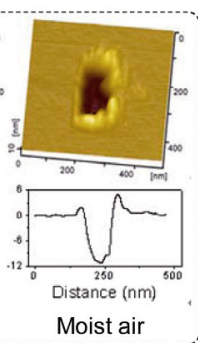

(b) Diamond tip

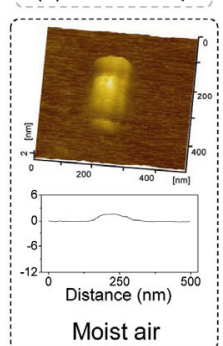

Fig. 13 Effect of environment and counter-face on nanowear of Si (100). (a) AFM images and profiles of nanowear scars on Si (100) surface against $\mathrm{SiO}_{2}$ tip in various atmospheres (e.g., vacuum, nitrogen, oxygen, dry air, and humid air). (b) AFM image and profile of nanowear scar on Si (100) surface against diamond tip in humid air; RH was $\sim 35 \%$. For all tests, the applied load and total sliding cycle were $5 \mu \mathrm{N}$ and 200, respectively. Reproduced with permission from Ref. [142], (C) American Chemical Society 2012 . 

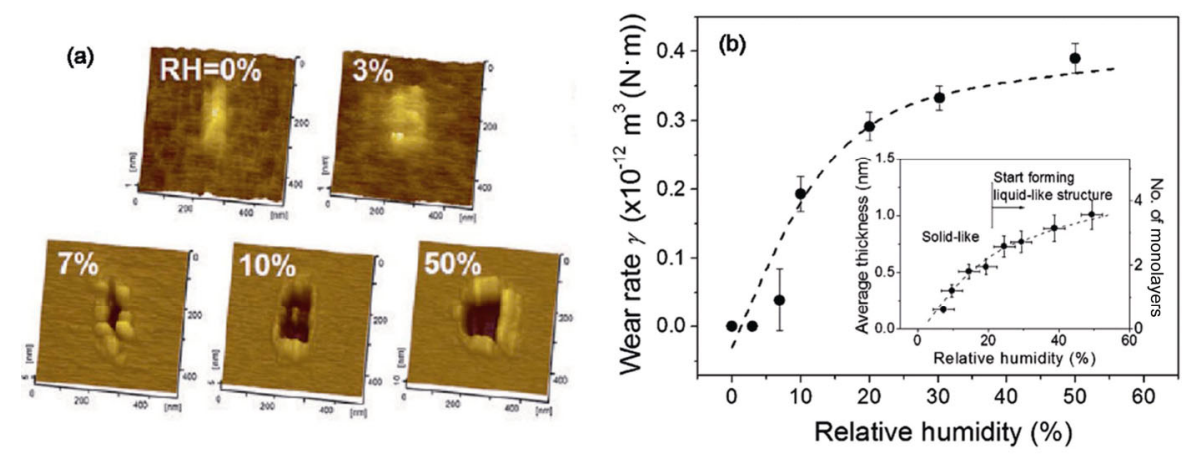

Fig. 14 Tribochemical wear of oxide-covered Si sliding against $\mathrm{SiO}_{2}$ tip at various $\mathrm{RH}$ values. (a) AFM images of wear scars on silicon surface at representative RH values; applied load, sliding speed, and sliding cycle were $3 \mu \mathrm{N}, 2 \mu \mathrm{m} / \mathrm{s}$, and 200 , respectively. (b) Wear rate is a function of $\mathrm{RH}$; inset shows adsorption isotherm of native oxide-covered Si (100) surface in humid air. Reproduced with permission from Ref. [142], (C) American Chemical Society 2012.

on the characterizations using the ATR-IR and SFG spectroscopies, Barnette and Kim [154] found that alcohol molecules could compete with water molecules to adsorb on the (relatively) hydrophilic solid surface. Chen et al. [155] and Marchand et al. [156] confirmed that ethanol vapor can effectively protect the Si surface against tribochemical wear. When $\mathrm{RH}$ was less than $50 \%$, there was a critical ethanol partial pressure beyond which the tribochemical reaction was completely suppressed, and no wear was generated on the Si surface. At an RH exceeding 50\%, the tribochemical wear on Si could be significantly (but not completely) reduced with the increase in the partial pressure of ethanol.

In general, the tribochemical wear becomes more severe at a higher $\mathrm{RH}$ and lower sliding speed (more contact time) or on a more hydrophilic solid surface. This is because of the enhancements in surficial water adsorption and interfacial meniscus condensation when the interfacial water is dominated by an ice-like structure. It is noteworthy that the effect of $\mathrm{RH}$ on the tribochemical wear is complex. For example, the tribochemical wear of native oxide-covered $\mathrm{Si}$ first increased to a maximum value at approximately $50 \% \mathrm{RH}$ and then decreased below the detection limit at a $\mathrm{RH}$ exceeding $85 \%$ or in water [134]. However, the tribochemical wear of $\mathrm{Si}$ after the removal of the native oxide layer monotonously increased as the $\mathrm{RH}$ increased from $0 \%$ to a practically saturated condition [157]. This difference should originate from the diverse capability of water adsorption and different water structures depending on the surface wettability (Fig. 4), which are discussed in the next section.

\subsection{Tribochemical wear suppressed by liquid-like water}

The participation of water in tribochemical reaction can facilitate material removal especially at a low contact pressure; however, excessive amounts of adsorbed water may lubricate the sliding interface and suppress the tribochemical wear. Wang et al. [38] compared the nanowear of $\mathrm{Si}$ (covered by native oxide layer) against a $\mathrm{SiO}_{2}$ AFM tip at RH values of $60 \%$ and $90 \%$. They found that the tribochemical wear (severe material removal) of the Si formed at $60 \% \mathrm{RH}$ was completely restrained until $\mathrm{RH}$ was increased to $90 \%$. Similar results were observed in the duplicate experiments (Fig. 15). These results indicated that the disappearance of tribochemical wear at $90 \% \mathrm{RH}$ was not due to the lubrication of reaction products, such as $\mathrm{Si}(\mathrm{OH})_{x}$, which were formed in the previous sliding tests at $60 \% \mathrm{RH}$ [158-161]. Both the experimental and computational results indicated that the interfacial water cannot be completely squeezed out from the contact area [39, 40, 162]. The MD simulations from Leng [41] demonstrated the hydration of the confined water molecules between two mica contact surfaces, which were capable of supporting a large load ( 1.5 GPa), increased the viscosity of the confined water to be approximately 5-16 times of bulk water when the interfacial water 

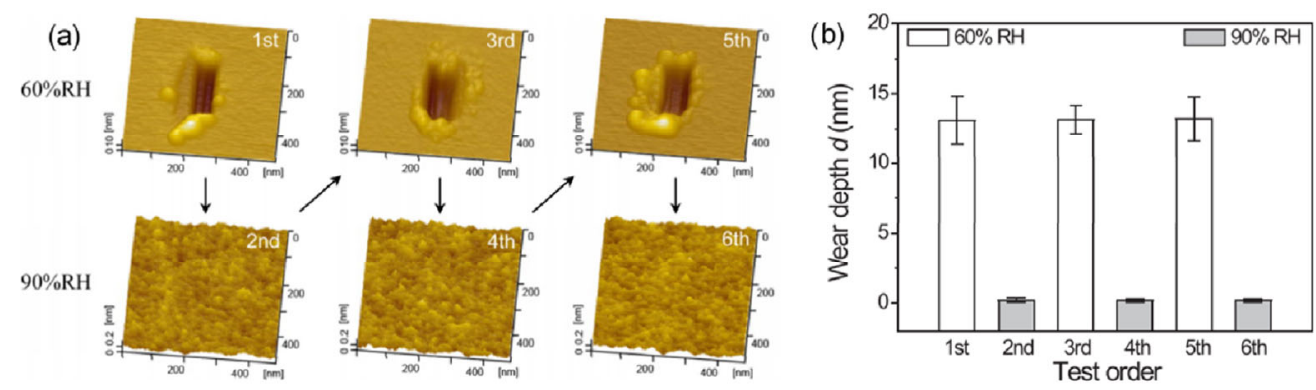

Fig. 15 Nanowear of silicon against $\mathrm{SiO}_{2}$ tip in humid air with $\mathrm{RHs}$ of $60 \%$ and $90 \%$. (a) AFM images and (b) wear depth of nanowear tracks on silicon surface formed at $60 \%$ and $90 \% \mathrm{RH}$, respectively. Applied load, sliding speed, and sliding cycle were $3 \mu \mathrm{N}, 2 \mu \mathrm{m} / \mathrm{s}$, and 200. Reproduced with permission from Ref. [38], (C) American Physical Society 2016.

was reduced to two layers. In previous studies, Israelachvili and Wennerström [10] observed the monotonic short-range hydration force between the two mica surfaces when the separation was reduced to $<1.5 \mathrm{~nm}$ in their experiments. They attributed this phenomenon to the ordered layering of water molecules bound to hydrated surface groups. In contrast, the MD simulation results given by Leng [41] showed the domination of the liquid phase of the confined water layer between the two mica surfaces. Although it is difficult to directly characterize the structure of interfacial water with only a few layers, it is reasonable to conclude that the multilayers of interfacial water growth at a high $\mathrm{RH}$ can be retained at the hydrophilic $\mathrm{Si}$ and $\mathrm{SiO}_{2}$ contact interface. This reduces the probability for the asperities to be sufficiently close to interact during the sliding process. Recently, this description has been supported by MD simulations. Wang et al. [163] and Ootani et al. [164] simulated the tribochemical reactions at the sliding interface of silicon-based materials. They also clarified that the tribochemical reaction related to the formation of the Si-O-Si interfacial bonds was suppressed as the amount of interfacial water increased. When the water layer thickness exceeds the critical length of Si-O-Si interfacial bonds, the tribochemical reaction at the sliding interface cannot occur, and the tribochemical wear of Si-based materials are completely suppressed.

A similar RH dependence of surface wear was observed for the graphite/graphene sliding interface. Huang et al. [165] compared the tribological performance of graphene in dry nitrogen $(<5 \%)$ and $40 \%$ RH humid air. Different from the case in dry nitrogen, the friction coefficient maintained a more stable and lower value during the entire sliding process, and the graphene wear after 1,000 sliding cycles was considerably less severe in humid air (Fig. 16(a)). It is well known that graphite/graphene is an excellent candidate as solid lubricant in an ambient atmosphere; however, it fails to provide low friction and good wear resistance under dry conditions [166, 167]. A defect-free graphene plane has a significantly high mechanical strength (elastic modulus $=\sim 1 \mathrm{TPa}$ ) and no interior dangling bonds. Moreover, it is more probable for the graphite/graphene wear and related friction force instability to initiate from the step edge or defect [168-171]. The simulations performed by Qi et al. [172] showed that the tribochemical wear via the $\mathrm{C}-\mathrm{C}$ formation between the diamond tip and dangling bonds at the graphene step edge occurs under a dry condition, resulting in the abrasive wear of graphene (Fig. 16(b)). In contrast, the physisorbed water molecules or chemisorbed $\mathrm{H}$ and $\mathrm{OH}$ ions from water passivated the dangling bonds, suppressing the atomic removal (Fig. 16(c)) [173].

Based on Arrhenius equation, the chemical reaction rate usually has a positive correlation with temperature. However, tribochemical wear is determined by many factors, such as environment, mechanical properties (e.g., elastic modulus and hardness), and chemical properties (e.g., surface wettability and bond energy) of two solid contact surfaces, which may be sensitive to temperature. Hence, the tribochemical reaction may not be predicted by the Arrhenius equation alone. For 


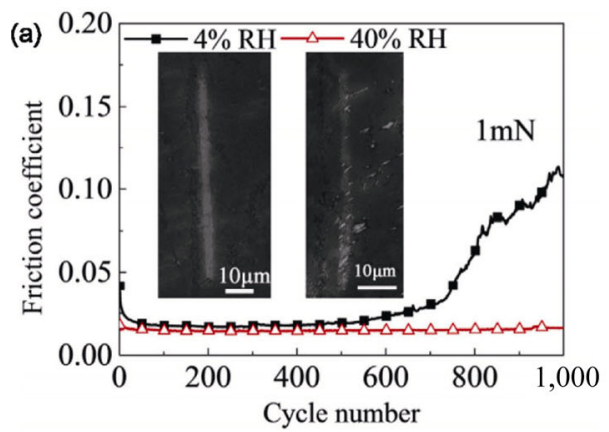

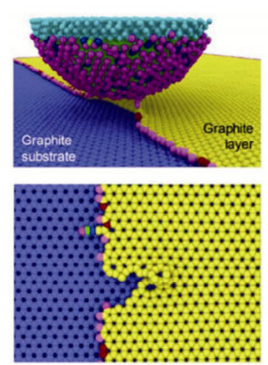

(b) Without water

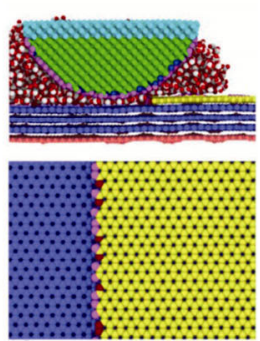

(c) With water

Fig. 16 RH-dependent wear of graphene in experiments and MD simulations. (a) Friction and wear behaviors of graphite in humid air with RH values of $4 \%$ and $40 \%$. Reproduced with permission from Ref. [165], (C) Elsevier 2017. (b, c) wear of graphene step edge against a diamond tip under conditions without and with water in MD simulations, respectively. Reproduced with permission from Ref. [172], (C) Elsevier 2018.

instance, Liu et al. [174] demonstrated the watertemperature dependence of tribochemical wear on two typical Si surfaces, involving oxide- covered Si partially terminated with hydroxyl groups and oxide-free Si fully terminated with hydrogen groups. As the water temperature increased from 10 to $80^{\circ} \mathrm{C}$, the tribochemical wear of the oxidecovered $\mathrm{Si}$ in water changed from a surface with no distinct damage to one with significant material removal. These occurred as the temperature gradually decreased on the oxide-free $\mathrm{Si}$ surface. The oxidefree Si surface became more hydrophilic at a higher water temperature, whereas the oxide-covered Si surface was more hydrophobic. Generally, the tribochemical wear on both Si surfaces decreased with the hydrophilization of the Si surface (growth of hydroxyl termination groups), allowing the retention of more interfacial water layers. Thereafter, the chemical reaction at the sliding interface in water was suppressed (Fig. 17). In a real CMP, the polishing rate of silicon wafer was also found to decrease with the increase in polishing temperature in the high-temperature regime [175]. This might be partially attributed to the temperature-enhanced growth of the surficial hydroxyl groups and thicker interfacial water. Furthermore, the polishing rate first increased to a maximum value at a critical $\mathrm{pH}$ and then decreased with the increase in the slurry $\mathrm{pH}$. This behavior was consistent with the variation in the hydrophobicity of the polished Si surface measured in room air [176], supporting the inhibition effect of the interfacial water on the tribochemical wear in water or slurry [177].
A similar phenomena where the tribochemical wear decreased at a high $\mathrm{RH}$ range was also observed on metal surfaces. Gore and Buckley [178] investigated the RH-dependent fretting wear of several pure metals involving steel, copper, silver, chromium, titanium, and nickel. The wear volumes of all these pure metals were found to increase at low $\mathrm{RH}$ values and decrease at high $\mathrm{RH}$ values from $0 \%$ to $80 \%$. The most severe surface wear occurred in the $\mathrm{RH}$ range $5 \%-20 \%$ depending on the metal [178]. As one of the most common materials of mechanical moving components, the tribological

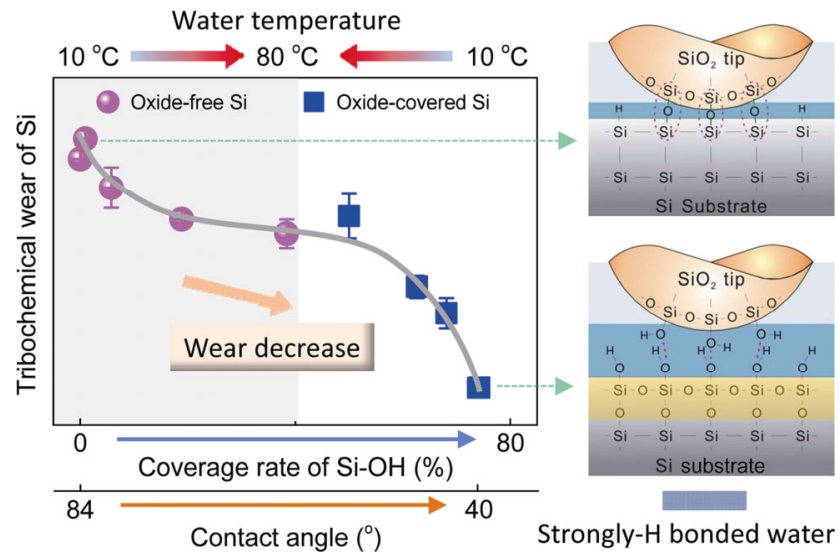

Fig. 17 Correlation between tribochemical wear and coverage rate of hydroxyl groups (surface wettability) on oxide-free $\mathrm{Si}$ and oxide-covered $\mathrm{Si}$ surfaces as water temperature ranges from 10 to $80{ }^{\circ} \mathrm{C}$. The solid line is drawn as guide. Right insets are schematics of mechanism of temperature-dependent tribochemical wear of silicon slide against $\mathrm{SiO}_{2}$ micro-sphere in deionized (DI) water with thin strongly hydrogen-bonded water layer for hydrophobic substrate case (upper inset) and thick strongly hydrogen-bonded water layer for hydrophilic substrate case (bottom inset). Reproduced with permission from Ref. [174], (C) American Chemical Society 2019. 
applications of steel are normally associated with the ionic liquid or oil lubrications (applications for hip joint, roller, and ball bearings) [179-183]. However, the effect of $\mathrm{RH}$ on the tribological properties of steel has previously attracted considerable interest because of the sensitivity of its nascent surface to water [184-186]. Without interface lubrication, severe damage may occur on the steel surface because of adhesion, delamination, and melting wear [187]. As the RH increases, the greater amount of adsorbed water facilitates the oxide layer growth on the worn steel surface, which can suppress the adhesive wear [188]. In summary, the interfacial water may lubricate the sliding interface depending on its thickness and structure, which are determined by the $\mathrm{RH}$, solution temperature, and $\mathrm{pH}$, or solid surface chemistry. An extremely thick water layer condensed at the contact interface at a high $\mathrm{RH}$ may restrain the formation of interfacial bridge bonds and reduce tribochemical reactions. The tribochemical wear that occurs in humid air is more severe on a more hydrophilic surface because of the enhancement of water adsorption [153]. The hydrophilization of the substrate surface facilitated by a higher solution temperature or $\mathrm{pH}$ can retain more interfacial water in the contact area under liquid conditions, which can separate the sliding interfaces and then suppress the tribochemical reactions.

\section{Summary and perspectives}

The interfacial water normally exhibits different structures and properties compared to the bulk water depending on the environment condition (i.e., RH), surface chemistry, and structure because of the additional interaction with a solid surface. On a hydrophilic surface, the adsorbed water, which consists of ordered (ice-like) structures with a strongly hydrogen-bonded network and disordered (liquid-like) structure formed at low and high $\mathrm{RH}$ values, respectively, can grow up to several layers in thickness. In contrast, the water layer on the hydrophobic surface is highly disordered and may behave as isolated clusters at high $\mathrm{RH}$ values.

The molecular configurations of the evolving interfacial water that depend on the vapor pressure, surface wettability, and structure have a strong influence on adhesion. The condensation of the ice-like meniscus on the hydrophilic surface at relatively low $\mathrm{RH}$ values increases the capillary force and rupture force of the ice-ice bridge at center of the contact region, resulting in the increase in adhesion force as the RH increases. However, the contribution of the ice-ice bridge rupture is suppressed by the growth of the liquid-like water at the outermost surface under high $\mathrm{RH}$ conditions, causing the reduction in the total adhesion force with further RH increase.

Typically, the capillary-related friction especially at hydrophilic interfaces is $\mathrm{RH}$-dependent and time-dependent before the thermodynamic equilibrium of meniscus growth is established. The enhancement of capillary condensation at a higher RH or longer contact time (slower sliding speed) corresponds to a large number of meniscus that form between the contacting and nearcontacting asperities in the multi-asperity contact model; it may also increase water bridge volume in the single-asperity contact model. Thereafter, the friction force gradually increases with the increase in the number of meniscus or water volume if the interfacial water is dominated by an ice-like structure at low RH values. The growth of the liquid-like water at high $\mathrm{RH}$ values suppresses the contact of the solid interface and then reduces the capillary-related friction force.

The water-associated tribochemical wear that occurs under contact pressure is considerably lower than the yield limit of materials and may be modeled using the stress-assisted chemical reaction kinetics. The interfacial water dominated by the ice-like structure can facilitate the tribochemical reaction and induce more severe material removal. A considerably thicker water layer (especially with a liquid-like structure) confined in the contact region separates two solid surfaces and then weakens the tribochemical reaction. The tribochemical wear may be completely suppressed when the interfacial water layer is sufficiently thick.

The configuration and condensation of the 
interfacial water dynamically depends on practically all critical factors involved in the tribological system, such as environmental conditions, properties, and status of contact surface. Therefore, further experimental and computational studies are still required to quantify the contribution of interfacial water to the tribological behaviors at the atomic or molecular level.

First, adhesion, friction, and wear at the nanoscale level were found to be significantly correlated with the thickness and structure of the adsorbed water layer. It is impossible to directly characterize experimentally the molecular configuration of the interfacial water within and around the microasperity/nanoasperity contact. Hence, its effect on nanotribology is normally inferred based on the structure evolution of the water layer already present on the solid surface before the contact. The dynamic structure and molecular details of the interfacial water especially in the confined region should be further determined by computational calculations or newly developed testing technologies.

Second, it is typically regarded that the capillaryrelated adhesion force caused by the water condensation has an equal contribution to the interfacial friction force at the nanoasperity contact as the imposed normal load. Previous studies have demonstrated that both the capillary- related adhesion force and related friction force may increase with the growth of ice-like water or decrease with the growth of liquid-like water. However, the change in the amplitudes of these two forces relatively differ. Therefore, the real relationship between the capillary-related adhesion and related friction should be determined especially with the consideration of the interfacial water structure.

Finally, newly developed techniques, such as in situ TEM, are capable of characterizing the atomic attrition process of nanoasperity in real time. It provides a direct evidence of the occurrence of the atom-by-atom removal caused by the tribochemical reaction. The limitation of this technology is that the water-associated tribochemical wear cannot be captured because it must be operated in a vacuum. It is difficult to fully deduce the underlying mechanism of tribochemical reaction with the participation of water based on the separate characterizations of worn surfaces or subsurfaces after the wear has formed. Computational calculations, such as MD simulation, can provide insight into the tribochemical wear mechanism; however, the contribution of interfacial water structure is usually not considered.

\section{Acknowledgements}

The authors are grateful for the financial support of the National Natural Science Foundation of China (Nos. 51991373 and 51875486) and Sichuan Science and Technology Program (2019YFH0098).

Open Access This article is licensed under a Creative Commons Attribution 4.0 International License, which permits use, sharing, adaptation, distribution and reproduction in any medium or format, as long as you give appropriate credit to the original author(s) and the source, provide a link to the Creative Commons licence, and indicate if changes were made.

The images or other third party material in this article are included in the article's Creative Commons licence, unless indicated otherwise in a credit line to the material. If material is not in-cluded in the article's Creative Commons licence and your intended use is not permitted by statutory regulation or exceeds the permitted use, you will need to obtain permission directly from the copyright holder.

To view a copy of this licence, visit http://creativecommons.org/licenses/by/4.0/.

\section{References}

[1] Björneholm O, Hansen M H, Hodgson A, Liu L M, Limmer D T, Michaelides A, Pedevilla P, Rossmeisl J, Shen H, Tocci G, et al. Water at interfaces. Chem Rev 116(13): 7698-7726 (2016)

[2] Ben-Naim A. Hydrophobic Interactions. New York (USA): Plenum Press, 1980.

[3] Raschke T M. Water structure and interactions with protein surfaces. Curr Opin Struct Biol 16(2): 152-159 (2006)

[4] Yang D S, Zewail A H. Ordered water structure at hydrophobic graphite interfaces observed by 4D, 
ultrafast electron crystallography. P Natl Acad Sci USA 106: 4122-4126 (2009)

[5] Ma R Z, Cao D Y, Zhu C Q, Tian Y, Peng J B, Guo J, Chen J, Li X Z, Francisco J S, Zeng X C, et al. Atomic imaging of the edge structure and growth of a twodimensional hexagonal ice. Nature 577(7788): 60-63 (2020)

[6] Yang J J, Meng S, Xu L F, Wang E G. Ice tessellation on a hydroxylated silica surface. Phys Rev Lett 92(14): 146102 (2004)

[7] Meleshyn A. Two-dimensional ordering of water adsorbed on a mica surface at room temperature. J Phys Chem C 112: 14495-14500 (2008)

[8] Fecko C J, Eaves J D, Loparo J J, Tokmakoff A, Geissler P L. Ultrafast hydrogen-bond dynamics in the infrared spectroscopy of water. Science 301(5640): 1698-1702 (2003)

[9] Wang H J, Xi X K, Kleinhammes A, Wu Y. Temperature-induced hydrophobic-hydrophilic transition observed by water adsorption. Science 322(5898): 80-83 (2008)

[10] Israelachvili J, Wennerström H. Role of hydration and water structure in biological and colloidal interactions. Nature 379(6562): 219-225 (1996)

[11] Bocquet L, Charlaix E, Ciliberto S, Crassous J. Moisture-induced ageing in granular media and the kinetics of capillary condensation. Nature 369(6713): 735-737 (1998)

[12] Hasz K, Ye Z J, Martini A, Carpick R W. Experiments and simulations of the humidity dependence of friction between nanoasperities and graphite: The role of interfacial contact quality. Phys Rev Mater 2(12): 126001 (2018)

[13] Bhushan B. Nanotribology and Nanomechanics: An Introduction. 2nd edn. Berlin (Germany): Springer, 2008.

[14] Bhushan B. Springer Handbook of Nanotechnology. Heidelberg (Germany): Springer-Verlag, 2004.

[15] Kim S H, Asay D B, Dugger M T. Nanotribology and MEMS. Nano Today 2(5): 22-29 (2007)

[16] Subhash G, Corwin A D, de Boer M P. Evolution of wear characteristics and frictional behavior in MEMS devices. Tribol Lett 41(1): 177-189 (2011)

[17] Ku I S Y, Reddyhoff T, Holmes A S, Spikes H A. Wear of silicon surfaces in MEMS. Wear 271(7-8): 10501058 (2011)

[18] Zhao Y P, Wang L S, Yu T X. Mechanics of adhesion in MEMS-a review. J Adhesion Sci Technol 17(4): 519546 (2003)

[19] Miller S L, Rodgers M S, La Vigne G, Sniegowski J J, Clews P, Tanner D M, Peterson K A. Failure modes in surface micromachined microelectromechanical actuation systems. Microelectron Reliab 39(8): 1229-1237 (1999)

[20] Asay D B, Dugger M T, Kim S H. In-situ vapor-phase lubrication of MEMS. Tribol Lett 29(1): 67-74 (2008)

[21] Asay D B, Dugger M T, Ohlhausen J A, Kim S H. Macro-to nanoscale wear prevention via molecular adsorption. Langmuir 24(1): 155-159 (2008)

[22] Fu J C, He H T, Yuan W F, Zhang Y F, Yu J X. Towards a deeper understanding of nanoscratch-induced deformation in an optical glass. Appl Phys Lett 113(3): 031606 (2018)

[23] Ribeiro R, Shan Z, Minor A M, Liang H. In situ observation of nano-abrasive wear. Wear 263(7-12): 1556-1559 (2007)

[24] Chen L, Hu L C, Xiao C, Qi Y Q, Yu B J, Qian L M. Effect of crystallographic orientation on mechanical removal of $\mathrm{CaF}_{2}$. Wear 376-377: 409-416 (2017)

[25] Chen L, Yang M C, Song C F, Yu B J, Qian L M. Is 2 $\mathrm{nm}$ DLC coating enough to resist the nanowear of silicon. Wear 302(1-2): 909-917 (2013)

[26] Katsuki F. Single asperity tribochemical wear of silicon by atomic force microscopy. J Mater Res 24(1): 173-178 (2009)

[27] Chen L, Yang M C, Yu J X, Qian L M, Zhou Z. Nanofretting behaviours of ultrathin DLC coating on Si(100) substrate. Wear 271(9-10): 1980-1986 (2011)

[28] Liu X X, Yu B J, Zou Y J, Zhou C, Li X Y, Wu J, Liu H Y, Chen L, Qian L M. Revealing silicon crystal defects by conductive atomic force microscope. Appl Phys Lett 113(10): 101601 (2018)

[29] Yu J X, He H T, Zhang Y F, Hu H L. Nanoscale mechanochemical wear of phosphate laser glass against a $\mathrm{CeO}_{2}$ particle in humid air. Appl Surf Sci 392: 523-530 (2017)

[30] Xiao C, Shi P F, Yan W M, Chen L, Qian L M, Kim S H. Thickness and structure of adsorbed water layer and effects on adhesion and friction at nanoasperity contact. Colloids Interfaces 3(3): 55 (2019)

[31] Zhou Y, Pan G S, Shi X L, Gong H, Xu L, Zou C L. AFM and XPS studies on material removal mechanism of sapphire wafer during chemical mechanical polishing (CMP). J Mater Sci: Mater Electron 26(12): 9921-9928 (2015)

[32] Wang L, Zhou P, Yan Y, Zhang B, Kang R K, Guo D M. Chemical-mechanical wear of monocrystalline silicon by a single pad asperity. Int J Mach Tools Manuf 120: 61-71 (2017)

[33] Si L N, Guo D, Luo J B, Lu X C, Xie G X. Abrasive rolling effects on material removal and surface finish in chemical mechanical polishing analyzed by molecular dynamics simulation. $J$ Appl Phys 109(8): 084335 (2011)

[34] Zhang P, Chen C, Xiao C, Chen L, Jiang L, Qian L M. 
Effects of surface chemical groups and environmental media on tribochemical running-in behaviors of silicon surface. Tribol Int 128: 174-180 (2018)

[35] Xiao C, Chen C, Wang H B, Chen L, Jiang L, Yu B J, Qian L M. Effect of counter-surface chemistry on defect-free material removal of monocrystalline silicon. Wear 426-427: 1233-1239 (2019)

[36] Xiao C, Guo J, Zhang P, Chen C, Chen L, Qian L M. Effect of crystal plane orientation on tribochemical removal of monocrystalline silicon. Sci Rep 7: 40750 (2017)

[37] Wang X D, Kim S H, Chen C, Chen L, He H T, Qian L M. Humidity dependence of tribochemical wear of monocrystalline silicon. ACS Appl Mater Interfaces 7(27): 14785-14792 (2015)

[38] Wang X D, Guo J, Chen C, Chen L, Qian L M. A simple method to control nanotribology behaviors of monocrystalline silicon. J Appl Phys 119(4): 044304 (2016)

[39] Liu S H, Luo J B, Li G, Zhang C H, Lu X C. Effect of surface physicochemical properties on the lubricating properties of water film. Appl Surf Sci 254(22): 71377142 (2008)

[40] Israelachvili J N, Pashley R M. Molecular layering of water at surfaces and origin of repulsive hydration forces. Nature 306(5940): 249-250 (1983)

[41] Leng Y S. Hydration force and dynamic squeeze-out of hydration water under subnanometer confinement. $J$ Phys: Condens Matter 20(35): 354017 (2008)

[42] Matsubara H, Pichierri F, Kuriha K. Mechanism of diffusion slowdown in confined liquids. Phys Rev Lett 109(19): 197801 (2012)

[43] Chandler D. Interfaces and the driving force of hydrophobic assembly. Nature 437(7059): 640-647 (2005)

[44] Chothia C, Janin J. Principles of protein-protein recognition. Nature 256(5520): 705-708 (1975)

[45] Strempel V E, Naumann d'Alnoncourt R, Driess M, Rosowski F. Atomic layer deposition on porous powders with in situ gravimetric monitoring in a modular fixed bed reactor setup. Rev Sci Instrum 88(7): 074102 (2017)

[46] Alazizi A, Barthel A J, Surdyka N D, Luo J W, Kim S H. Vapors in the ambient-A complication in tribological studies or an engineering solution of tribological problems? Friction 3(2): 85-114 (2015)

[47] Klei, J. Hydration lubrication. Friction 1(1): 1-23 (2013)

[48] Barnette A L, Asay D B, Kim D, Guyer B D, Lim H, Janik $M$ J, Kim S H. Experimental and density functional theory study of the tribochemical wear behavior of $\mathrm{SiO}_{2}$ in humid and alcohol vapor environments. Langmuir 25(22): 13052-13061 (2009)

[49] Lee C Y, McCammon J A, Rossky R J. The structure of liquid water at an extended hydrophobic surface. $J$ Chem Phys 80(9): 4448-4455 (1984)

[50] Carpenter I L, Hehre W J. A molecular dynamics study of the hexane/water interface. J Phys Chem 94(2): 531-536 (1990)

[51] Guyot-Sionnest P, Hunt J H, Shen Y R. Sum-frequency vibrational spectroscopy of a Langmuir film: Study of molecular orientation of a two-dimensional system. Phys Rev Lett 59(14): 1597-1600 (1987)

[52] Du Q, Superfine R, Freysz E, Shen Y R. Vibrational spectroscopy of water at the vapor/water interface. Phys Rev Lett 70(15): 2313-2316 (1993)

[53] Du Q, Freysz E, Shen Y R. Surface vibrational spectroscopic studies of hydrogen bonding and hydrophobicity. Science 264(5160): 826-828 (1994)

[54] Odelius M, Bernasconi M, Parrinello M. Two dimensional ice adsorbed on mica surface. Phys Rev Lett 78(14): 2855-2858 (1997)

[55] Aarts I M P, Pipino A C R, Hoefnagels J P M, Kessels W M M, van de Sanden M C M. Quasi-ice monolayer on atomically smooth amorphous $\mathrm{SiO}_{2}$ at room temperature observed with a high-finesse optical resonator. Phys Rev Lett 95(16): 166104 (2005)

[56] Mu R T, Zhao Z J, Dohnálek Z, Gong J L. Structural motifs of water on metal oxide surfaces. Chem $S o c$ Rev 46(7): 1785-1806 (2017)

[57] Phan A, Ho T A, Cole D R, Striolo A. Molecular structure and dynamics in thin water films at metal oxide surfaces: Magnesium, aluminum, and silicon oxide surfaces. J Phys Chem C 116(30): 15962-15973 (2012)

[58] Carrasco J, Hodgson A, Michaelides A. A molecular perspective of water at metal interfaces. Nat Mater 11(8): 667-674 (2012)

[59] Yang J J, Meng S, Xu L F, Wang E G. Ice tessellation on a hydroxylated silica surface. Phys Rev Lett 92(14): 146102 (2004)

[60] Argyris D, Cole D R, Striolo A. Dynamic behavior of interfacial water at the silica surface. J Phys Chem C 113(45): 19591-19600 (2009)

[61] Asay D B, Kim S H. Evolution of the adsorbed water layer structure on silicon oxide at room temperature. $J$ Phys Chem B 109(35): 16760-16763 (2005)

[62] Miranda P B, Xu L, Shen Y R, Salmeron M. Icelike water monolayer adsorbed on mica at room temperature. Phys Rev Lett 81(26): 5876-5879 (1998)

[63] Xu L, Lio A, Hu J, Ogletree D F, Salmeron M. Wetting and capillary phenomena of water on mica. $J$ Phys Chem B 102(3): 540-548 (1998)

[64] Gordillo M C, Martí J. Molecular dynamics description 
of a layer of water molecules on a hydrophobic surface. J Chem Phys 117(7): 3425-3430 (2002)

[65] Willard A P, Chandler D. The molecular structure of the interface between water and a hydrophobic substrate is liquid-vapor like. J Chem Phys 141(18): 18C519 (2014)

[66] Asay D B, Barnette A L, Kim S H. Effects of surface chemistry on structure and thermodynamics of water layers at solid-vapor interfaces. J Phys Chem C 113(6): 2128-2133 (2009)

[67] Chen L, He X, Liu H S, Qian L M, Kim S H. Water adsorption on hydrophilic and hydrophobic surfaces of silicon. J Phys Chem C 122(21): 11385-11391 (2018)

[68] Ohba T, Kanoh H, Kaneko K. Cluster-growth-induced water adsorption in hydrophobic carbon nanopores. $J$ Phys Chem B 108(39): 14964-14969 (2004)

[69] Chen L, Ngo D, Luo J W, Gong Y F, Xiao C, He X, Yu B J, Qian L M, Kim S H. Dependence of water adsorption on the surface structure of silicon wafers aged under different environmental conditions. Phys Chem Chem Phys 21(47): 26041-26048 (2019)

[70] Baumgartner B, Hayden J, Loizillon J, Steinbacher S, Grosso D, Lendl B. Pore size-dependent structure of confined water in mesoporous silica films from water adsorption/desorption using ATR-FTIR spectroscopy. Langmuir 35(37): 11986-11994 (2019)

[71] Szoszkiewicz R, Riedo E. Nucleation time of nanoscale water bridges. Phys Rev Lett 95(13): 135502 (2005)

[72] McFarlane J S, Tabor D. Adhesion of solids and the effect of surface films. Proc Roy Soc London. Ser A, Math Phys Sci 202(1069): 224-243 (1950)

[73] Israelachvili J N. Intermolecular and Surface Forces. 2nd edn. London (UK): Academic Press Inc., 1992.

[74] Xiao X D, Qian L M. Investigation of humiditydependent capillary force. Langmuir 16(21): 81538158 (2000)

[75] Yu J X, Chen L, Qian L M, Song D L, Cai Y. Investigation of humidity-dependent nanotribology behaviors of $\mathrm{Si}(100) / \mathrm{SiO}_{2}$ pair moving from stick to slip. Appl Surf Sci 265: 192-200 (2013)

[76] Bartošík M, Kormoš L, Flajšman L, Kalousek R, Mach J, Lišková Z, Nezval D, Švarc V, Šamořil T, Šikola T. Nanometer-sized water bridge and pull-off force in AFM at different relative humidities: Reproducibility measurement and model based on surface tension change. J Phys Chem B 121(3): 610-619 (2017)

[77] Ye Z J, Egberts P, Han G H, Johnson A T C, Carpick R $\mathrm{W}$, Martini A. Load-dependent friction hysteresis on graphene. ACS Nano 10(5): 5161-5168 (2016)

[78] Kralchevsky P A, Nagayama K. Particles at Fluid Interfaces and Membranes: Attachment of Colloid Particles and Proteins to Interfaces and Formation of Two-Dimensional Arrays. Amsterdam (Netherlands):
Elsevier: Amsterdam, 2001.

[79] Wan K T, Smith D T, Lawn B R. Fracture and contact adhesion energies of mica-mica, silica-silica, and mica-silica interfaces in dry and moist atmospheres. $J$ Am Ceram Soc 75(3): 667-676 (1992)

[80] Yang L, Hu J H, Xiao H P, Quan W W. Analysis of humidity-dependent adhesion between a probe tip and a surface. Particuology 33: 91-97 (2017)

[81] Douillard J M, Henry M. Calculation of surface enthalpy of solids from an $a b$ initio electronegativity based model: Case of ice. J Colloid Interface Sci 263(2): 554-561 (2003)

[82] Kuroda Y, Kittaka S, Takahara S, Yamaguchi T, Bellissent-Funel M C. Characterization of the state of two-dimensionally condensed water on hydroxylated chromium(III) oxide surface through FT-IR, quasielastic neutron scattering, and dielectric relaxation measurements. J Phys Chem B 103(50): 11064-11073 (1999)

[83] Asay D B, Kim S H. Effects of adsorbed water layer structure on adhesion force of silicon oxide nanoasperity contact in humid ambient. $J$ Chem Phys 124(17): 174712 (2006)

[84] Mahoney M W, Jorgensen W L. A five-site model for liquid water and the reproduction of the density anomaly by rigid, nonpolarizable potential functions. $J$ Chem Phys 112(20): 8910-8922 (2000)

[85] Xiao C, Chen C, Yao Y Y, Liu H S, Chen L, Qian L M, Kim S H. Nanoasperity adhesion of the silicon surface in humid air: The roles of surface chemistry and oxidized layer structure. Langmuir 36(20): 5483-5491 (2020)

[86] Putman C A J, Igarashi M, Kaneko R. Single-asperity friction in friction force microscopy: The composite-tip model. Appl Phys Lett 66(23): 3221-3223 (1995)

[87] Gnecco E, Bennewitz R, Gyalog T, Loppacher C, Bammerlin M, Meyer E, Güntherodt H J. Velocity dependence of atomic friction. Phys Rev Lett 84(6): 1172-1175 (2000)

[88] Liu H W, Ahmed S I U, Scherge M. Microtribological properties of silicon and silicon coated with diamond like carbon, octadecyltrichlorosilane and stearic acid cadmium salt films: A comparative study. Thin Solid Films 381(1): 135-142 (2001)

[89] Zwörner O, Hölscher H, Schwarz U D, Wiesendanger R. The velocity dependence of frictional forces in point-contact friction. Appl Phys A 66(S1): S263-S267 (1998)

[90] Tambe N S, Bhushan B. Friction model for the velocity dependence of nanoscale friction. Nanotechnology 16(10): 2309-2324 (2005)

[91] Riedo E, Lévy F, Brune H. Kinetics of capillary 
condensation in nanoscopic sliding friction. Phys Rev Lett 88(18): 185505 (2002)

[92] Chen S H, Soh A K. The capillary force in micro- and nano-indentation with different indenter shapes. Int $J$ Solids Struct 45(10): 3122-3137 (2008)

[93] Kopycinska-Müller M, Geiss R H, Hurley D C. Contact mechanics and tip shape in AFM-based nanomechanical measurements. Ultramicroscopy 106(6): 466-474 (2006)

[94] Yang S, Zhang H, Nosonovsky M, Chung K H. Effects of contact geometry on pull-off force measurements with a colloidal probe. Langmuir 24(3): 743-748 (2008)

[95] Ata A, Rabinovich Y I, Singh R K. Role of surface roughness in capillary adhesion. $J$ Adhes Sci Technol 16(4): 337-346 (2002)

[96] Al-Azizi A A, Eryilmaz O, Erdemir A, Kim S H. Effects of nanoscale surface texture and lubricant molecular structure on boundary lubrication in liquid. Langmuir 29(44): 13419-13426 (2013)

[97] Paul J, Meltzer M, Braunschweig B, Peukert W. Lubrication of individual microcontacts by a selfassembled alkyl phosphonic acid monolayer on $\alpha-\mathrm{Al}_{2} \mathrm{O}_{3}$ (0001). Langmuir 32(33): 8298-8306 (2016)

[98] Chen L, Xiao C, Yu B J, Kim S H, Qian L M. What governs friction of silicon oxide in humid environment: Contact area between solids, water meniscus around the contact, or water layer structure? Langmuir 33(38): 9673-9679 (2017)

[99] Chen J Y, Ratera I, Park J Y, Salmeron M. Velocity dependence of friction and hydrogen bonding effects. Phys Rev Lett 96(23): 236102 (2006)

[100] Schumacher A, Kruse N, Prins R, Meyer E, Lüthi R, Howald L, Güntherodt H J, Scandella L. Influence of humidity on friction measurements of supported $\mathrm{MoS}_{2}$ single layers. J Vac Sci Technol B 14(2): 1264-1267 (1996)

[101] Asay D B, de Boer M P, Kim S H. Equilibrium vapor adsorption and capillary force: Exact laplace-young equation solution and circular approximation approaches. J Adhes Sci Technol 24(15): 2363-2382 (2010)

[102] Rhee T H, Shin M W, Jang H. Effects of humidity and substrate hydrophilicity on nanoscale friction. Tribol Int 94: 234-239 (2016)

[103] Akaishi A, Yonemaru T, Nakamura J. Formation of water layers on graphene surfaces. ACS Omega 2(5): 2184-2190 (2017)

[104] Greiner C, Felts J R, Dai Z T, King W P, Carpick R W. Controlling nanoscale friction through the competition between capillary adsorption and thermally activated sliding. ACS Nano 6(5): 4305-4313 (2012)

[105] Bhushan B, Israelachvili $J \quad N$, Landman $U$. Nanotribology: Friction, wear and lubrication at the atomic scale. Nature 374(6523): 607-616 (1995)

[106]Zarudi I, Cheong W C D, Zou J, Zhang L C. Atomistic structure of monocrystalline silicon in surface nanomodification. Nanotechnology 15(1): 104-107 (2004)

[107] Neo W K, Kumar A S, Rahman M. A review on the current research trends in ductile regime machining. Int J Adv Manuf Technol 63(5-8): 465-480 (2012)

[108] Mizumoto Y, Aoyama T, Kakinuma Y. Basic study on ultraprecision machining of single-crystal calcium fluoride. Proc Eng 19: 264-269 (2011)

[109] Yuan S, Guo X G, Lu M G, Jin Z J, Kang R. K, Guo D M. Diamond nanoscale surface processing and tribochemical wear mechanism. Diam Relat Mater 94: 8-13 (2019)

[110]Khatib R, Backus E H G, Bonn M, Perez-Haro M J, Gaigeot M, Sulpizi M. Water orientation and hydrogenbond structure at the fluorite/water interface. Sci Rep 6: 24287 (2016)

[111] Guo J, Gong J, Shi P F, Xiao C, Jiang L, Chen L, Qian L M. Study on the polishing mechanism of $\mathrm{pH}$-dependent tribochemical removal in $\mathrm{CMP}$ of $\mathrm{CaF}_{2}$ crystal. Tribol Int 150: 106370 (2020)

[112] Jacobs T D B, Carpick R W. Nanoscale wear as a stress-assisted chemical reaction. Nat Nanotechnol 8(2): 108-112 (2013)

[113] Chen L, He H T, Wang X D, Kim S H, Qian L M. Tribology of $\mathrm{Si} / \mathrm{SiO}_{2}$ in humid air: Transition from severe chemical wear to wearless behavior at nanoscale. Langmuir 31(1): 149-156 (2015)

[114]Maluf N, Williams K. An Introduction to Microelectromechanical Systems Engineering. 2nd edn. London (UK): Artech House, 2004.

[115] Wen J L, Ma T B, Zhang W W, Psofogiannakis G, van Duin A C T, Chen L, Qian L M, Hu Y Z, Lu X C. Atomic insight into tribochemical wear mechanism of silicon at the $\mathrm{Si} / \mathrm{SiO}_{2}$ interface in aqueous environment: Molecular dynamics simulations using ReaxFF reactive force field. Appl Surf Sci 390: 216-223 (2016)

[116] Chen L, Wen J L, Zhang P, Yu B J, Ma T B, Lu X C, Kim S H, Qian L M. Nanomanufacturing of silicon surface with a single atomic layer precision via mechanochemical reactions. Nat Commun 9(1): 1542 (2018)

[117] Wang M, Duan F L. Atomic-level wear behavior of sliding between silica (010) surfaces. Appl Surf Sci 425: 1168-1175 (2017)

[118] Archard J F. Contact and rubbing of flat surfaces. $J$ Appl Phys 24(8): 981-988 (1953)

[119] Boscoboinik A, Olson D, Adams H, Hopper N, Tysoe W T. Measuring and modelling mechanochemical reaction kinetics. Chem Commun 56(56): 7730-7733 (2020)

[120]Chen L, Xiao C, He X, Yu B J, Kim S H, Qian L M. 
Friction and tribochemical wear behaviors of native oxide layer on silicon at nanoscale. Tribol Lett 65(4): 139 (2017)

[121] Sheehan P E. The wear kinetics of $\mathrm{NaCl}$ under dry nitrogen and at low humidities. Chem Phys Lett 410(1-3): 151-155 (2005)

[122] Gotsmann B, Lantz M A. Atomistic wear in a single asperity sliding contact. Phys Rev Lett 101(12): 125501 (2008)

[123] Liu J J, Jiang Y J, Grierson D S, Sridharan K, Shao Y C, Jacobs T D B, Falk M L, Carpick R W, Turner K T. Tribochemical wear of diamond-like carbon-coated atomic force microscope tips. ACS Appl Mater Interfaces 9(40): 35341-35348 (2017)

[124] Shao Y C, Jacobs T D B, Jiang Y J, Turner K T, Carpick R W, Falk M L. Multibond model of single-asperity tribochemical wear at the nanoscale. ACS Appl Mater Interfaces 9(40): 35333-35340 (2017)

[125] Yang Y J, Huang L P, Shi Y F. Adhesion suppresses atomic wear in single-asperity sliding. Wear 352-353: 31-41 (2016)

[126] Yang Y J, Shi Y F. Single asperity friction in the wear regime. Friction 6(3): 316-322 (2018)

[127] Wang Y, Yamada N, Xu J X, Zhang J, Chen Q, Ootani Y, Higuchi Y, Ozawa N, Bouchet M I D B, Martin J M, et al. Triboemission of hydrocarbon molecules from diamond-like carbon friction interface induces atomicscale wear. Sci Adv 5(11): eaax9301 (2019)

[128] Yue D C, Ma T B, Hu Y Z, Yeon J, van Duin A C T, Wang H, Luo J B. Tribochemical mechanism of amorphous silica asperities in aqueous environment: A reactive molecular dynamics study. Langmuir 31(4): 1429-1436 (2015)

[129] Wen J L, Ma T B, Zhang W W, van Duin A C T, van Duin D M, Hu Y Z, Lu X C. Atomistic insights into $\mathrm{Cu}$ chemical mechanical polishing mechanism in aqueous hydrogen peroxide and glycine: ReaxFF reactive molecular dynamics simulations. J Phys Chem C 123: 26467-26474 (2019)

[130] Dante R C, Kajdas C K. A review and a fundamental theory of silicon nitride tribochemistry. Wear 288: $27-$ 38 (2012)

[131] Sharma S K, Kumar B V M, Kim Y W. Tribological behavior of silicon carbide ceramics-A review. $J$ Korean Ceram Soc 53(6): 581-596 (2016)

[132] Jacobs T D B, Gotsmann B, Lantz M A, Carpick R W. On the application of transition state theory to atomic-scale wear. Tribol Lett 39(3): 257-271 (2010)

[133] Chen Z, He X, Xiao X, Kim S H. Effect of humidity on friction and wear-A critical review. Lubricants $6(3)$ : 74 (2018)

[134] Xiao C, Li J, Guo J, Zhang P, Yu B, Chen L, Qian L M.
Role of mechanically-driven distorted microstructure in mechanochemical removal of silicon. Appl Surf Sci 520: 146337 (2020)

[135] Yu J, Yuan W, Hu H, Zang H, Cai Y, Ji F. Nanoscale friction and wear of phosphate laser glass and bk7 glass against single $\mathrm{CeO}_{2}$ particle by AFM. J Am Ceram Soc 98: 1111-1120 (2015)

[136] Yu J X, Yuan W F, Hu H L, Zang H B, Cai Y, Ji F. Nanoscale friction and wear of phosphate laser glass and $\mathrm{BK} 7$ glass against single $\mathrm{CeO}_{2}$ Particle by AFM. $J$ Am Ceram Soc 98(4): 1111-1120 (2015)

[137] He H T, Kim S H, Qian L M. Effects of contact pressure, counter-surface and humidity on wear of soda-limesilica glass at nanoscale. Tribol Int 94: 675-681 (2016)

[138] Yu B J, Gao J, Jin C N, Xiao C, Wu J, Liu H Y, Jiang S L, Chen L, Qian L M. Humidity effects on tribochemical removal of GaAs surfaces. Appl Phys Exp 9(6): 066703 (2016)

[139]Basu B, Vitchev R G, Vleugels J, Celis J P, Van Der Biest $O$. Influence of humidity on the fretting wear of self-mated tetragonal zirconia ceramics. Acta Mater 48(10): 2461-2471 (2000)

[140] Parsaeian R, Van Eijk M C P, Nedelcu I, Neville A, Morina A. Study of the interfacial mechanism of ZDDP tribofilm in humid environment and its effect on tribochemical wear; Part I: Experimental. Tribol Int 107: 135-143 (2017)

[141] Kim D K, Fischer T E, Gallois B. The effects of oxygen and humidity on friction and wear of diamond-like carbon films. Surf Coat Technol 49(1-3): 537-542 (1991)

[142] Yu J X, Kim S H, Yu B J, Qian L M, Zhou Z R. Role of tribochemistry in nanowear of single-crystalline silicon. ACS Appl Mater Interfaces 4(3): 1585-1593 (2012)

[143] Yu B J, Qian L M, Dong H S, Yu J X, Zhou Z R. Friction-induced hillocks on monocrystalline silicon in atmosphere and in vacuum. Wear 268(9-10): 10951102 (2010)

[144] Yu B J, Dong H S, Qian L M, Chen Y F, Yu J X, Zhou Z R. Friction-induced nanofabrication on monocrystalline silicon. Nanotechnology 20(46): 465303 (2009)

[145]Zhang P, He H T, Chen C, Xiao C, Chen L, Qian L M. Effect of abrasive particle size on tribochemical wear of monocrystalline silicon. Tribol Int 109: 222-228 (2017)

[146] Wang X D, Guo J, Xu L, Cheng G, Qian L M. An investigation of the wear on silicon surface at high humidity. Materials 11: 1027 (2018)

[147] Guo J, Yu B J, Chen L, Qian L M. Nondestructive nanofabrication on $\mathrm{Si}(100)$ surface by tribochemistryinduced selective etching. Sci Rep 5: 16472 (2015)

[148] Meng Y G, Xu J, Jin Z M, Prakash B, Hu Y Z. A review of recent advances in tribology. Friction 8(2): 221-300 (2020) 
[149] Yu J X, Qian L M, Yu B J, Zhou Z R. Nanofretting behaviors of monocrystalline silicon (100) against diamond tips in atmosphere and vacuum. Wear 267(14): 322-329 (2009)

[150] Xiao C, Chen C, Guo J, Zhang P, Chen L, Qian L M. Threshold contact pressure for the material removal on monocrystalline silicon by $\mathrm{SiO}_{2}$ microsphere. Wear 376-377: 188-193 (2017)

[151] Chen L, Qi Y Q, Yu B J, Qian L M. Sliding speed-dependent tribochemical wear of oxide-free silicon. Nanoscale Res Lett 12(1): 404 (2017)

[152]Zhang P, Chen C, Xiao C, Chen L, Qian L M. Comparison of wear methods at nanoscale: Line scanning and area scanning. Wear 400-401: 137-143 (2018)

[153] Yu J X, Qian L M, Yu B J, Zhou Z R. Effect of surface hydrophilicity on the nanofretting behavior of $\mathrm{Si}(100)$ in atmosphere and vacuum. J Appl Phys 108(3): 034314 (2010)

[154] Barnette A L, Kim S H. Coadsorption of $n$-propanol and water on $\mathrm{SiO}_{2}$ : Study of thickness, composition, and structure of binary adsorbate layer using attenuated total reflection infrared (ATR-IR) and sum frequency generation (SFG) vibration spectroscopy. J Phys Chem C 116(18): 9909-9916 (2012)

[155] Chen L, Yang Y J, He H T, Kim S H, Qian L M. Effect of coadsorption of water and alcohol vapor on the nanowear of silicon. Wear 332-333: 879-884 (2015)

[156] Marchand D J, Chen L, Meng Y G, Qian L M, Kim S H. Effects of vapor environment and counter-surface chemistry on tribochemical wear of silicon wafers. Tribol Lett 53(1): 365-372 (2014)

[157] Chen C, Xiao C, Wang X D, Zhang P, Chen L, Qi Y Q, Qian L M. Role of water in the tribochemical removal of bare silicon. Appl Surf Sci 390: 696-702 (2016)

[158] Yan W M, Gong J, Yu B J, Chen L, Qian L M. Self-lubrication of $\mathrm{Si} / \mathrm{SiO}_{2}$ interface achieved through running-in at low sliding speed. Wear 426-427: 828-834 (2019)

[159] Harrison J A, Stuart S J, Brenner D W. Atomic-scale simulations of tribological and related phenomena. In: Handbook of Micro/Nano Tribology. Bhushan B, Ed. Boca Raton: CRC Press, 1999.

[160] Mizuhara K, Hsu S M. Paper VII (viii) Tribochemical reaction of oxygen and water on silicon surfaces. Tribol Ser 21: 323-328 (1992)

[161] Chen L, Kim S H, Wang X D, Qian L M. Running-in process of $\mathrm{Si}-\mathrm{SiO}_{x} / \mathrm{SiO}_{2}$ pair at nanoscale-Sharp drops in friction and wear rate during initial cycles. Friction 1(1): 81-91 (2013)

[162] Leng Y S, Cummings P T. Hydration structure of water confined between mica surfaces. J Chem Phys 124(7): 074711 (2006)
[163] Wang M, Duan F L, Mu X J. Effect of surface silanol groups on friction and wear between amorphous silica surfaces. Langmuir 35(16): 5463-5470 (2019)

[164] Ootani Y, Xu J X, Hatano T, Kubo M. Contrasting roles of water at sliding interfaces between silicon-based materials: First-principles molecular dynamics sliding simulations. J Phys Chem C 122(19): 10459-10467 (2018)

[165]Huang Y H, Yao Q Z, Qi Y Z, Cheng Y, Wang H T, Li Q Y, Meng Y G. Wear evolution of monolayer graphene at the macroscale. Carbon 115: 600-607 (2017)

[166] Bhowmick S, Banerji A, Alpas A T. Role of humidity in reducing sliding friction of multilayered graphene. Carbon 87: 374-384 (2015)

[167] Yen B K. Influence of water vapor and oxygen on the tribology of carbon materials with $\mathrm{sp}^{2}$ valence configuration. Wear 192(1-2): 208-215 (1996)

[168]Qi Y Z, Liu J, Zhang J, Dong Y L, Li Q Y. Wear resistance limited by step edge failure: The rise and fall of graphene as an atomically thin lubricating material. ACS Appl Mater Interfaces 9(1): 1099-1106 (2017)

[169] Chen L, Chen Z, Tang X Y, Yan W M, Qian L M, Kim S H. Friction at single-layer graphene step edges due to chemical and topographic interactions. Carbon 154: 67-73 (2019)

[170]Zheng F, Duan F L. Atomistic mechanism of the weakened wear resistance of few-layer graphene induced by point defects. Tribol Int 134: 87-92 (2019)

[171]Zhang J, Chen X C, Xu Q, Ma T B, Hu Y Z, Wang H, Tieu A K, Luo J B. Effects of grain boundary on wear of graphene at the nanoscale: A molecular dynamics study. Carbon 143: 578-586 (2019)

[172] Qi Y Z, Liu J, Dong Y L, Feng X Q, Li Q Y. Impacts of environments on nanoscale wear behavior of graphene: Edge passivation vs. substrate pinning. Carbon 139: 59-66 (2018)

[173] Levita G, Restuccia P, Righi M C. Graphene and $\mathrm{MoS}_{2}$ interacting with water: A comparison by $a b$ initio calculations. Carbon 107: 878-884 (2016)

[174] Liu Z H, Gong J, Xiao C, Shi P F, Kim S H, Chen L, Qian L M. Temperature-dependent mechanochemical wear of silicon in water: The role of $\mathrm{Si}-\mathrm{OH}$ surfacial groups. Langmuir 35(24): 7735-7743 (2019)

[175]Liu J Q, Zhang C H, Ye W. Simulation on temperature distribution in chemical mechanical polishing. Key Eng Mater 353-358: 1671-1674 (2007)

[176] Wang Y G, Zhang L C, Biddut A. Chemical effect on the material removal rate in the CMP of silicon wafers. Wear 270(3-4): 312-316 (2011)

[177] Pietsch G J, Higashi G S, Chabal Y J. Chemomechanical polishing of silicon: Surface termination and mechanism of removal. Appl Phys Lett 64(23): 3115-3117 (1994) 
[178] Gore H, Buckley D H. The influence of water vapour in air on the friction behaviour of pure metals during fretting. Tribol Int 18(4): 237-245 (1985)

[179] Lancaster J K. A review of the influence of environmental humidity and water on friction, lubrication and wear. Tribol Int 23(6): 371-389 (1990)

[180]Wimmer M A, Fischer A, Büscher R, Pourzal R, Sprecher C, Hauert R, Jacobs J J. Wear mechanisms in metal-on-metal bearings: The importance of tribochemical reaction layers. J Orthop Res 28(4): 436-443 (2010)

[181] Spikes H. The history and mechanisms of ZDDP. Tribol Lett 17(3): 469-489 (2004)

[182] Chen Z, Liu Y H, Gunsel S, Luo J B. Mechanism of antiwear property under high pressure of synthetic oil-soluble ultrathin $\mathrm{MoS}_{2}$ sheets as lubricant additives. Langmuir 34(4): 1635-1644 (2018)

[183] Cen H, Morina A, Neville A, Pasaribu R, Nedelcu I. Effect of water on ZDDP anti-wear performance and related tribochemistry in lubricated steel/steel pure sliding contacts. Tribol Int 56: 47-57 (2012)

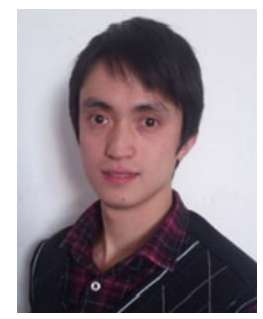

Lei CHEN. He is an associate professor of mechanical engineering at Southwest Jiaotong University (SWJTU) in China. He received his Ph.D. degree from SWJTU in 2013. He acted as a visiting scholar in The Pennsylvania State

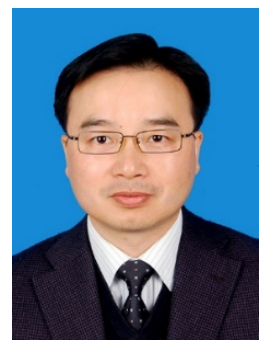

Linmao QIAN. He is a professor of mechanical engineering at SWJTU in China. He received his B.S. (1994) and Ph.D. (2000) degrees in mechanical engineering from Tsinghua University in China. After two years at Ecole Normale Supérieure in Paris and one year at Hong Kong University of Science and Technology as a postdoctoral researcher, he joined the faculty at SWJTU in 2002. His research interests include
[184]Klaffke D. On the repeatability of friction and wear results and on the influence of humidity in oscillating sliding tests of steel-steel pairings. Wear 189(1-2): 117-121 (1995)

[185]Bregliozzi G, Di Schino A, Kenny J M, Haefke H. The influence of atmospheric humidity and grain size on the friction and wear of AISI 304 austenitic stainless steel. Mater Lett 57(29): 4505-4508 (2003)

[186] Oh H K, Yeon K H, Kim H Y. The influence of atmospheric humidity on the friction and wear of carbon steels. J Mater Process Technol 95(1-3): 10-16 (1999)

[187] Wang Y, Lei T Q. Wear behavior of steel 1080 with different microstructures during dry sliding. Wear 194(1-2): 44-53 (1996)

[188] Wang Y, Lei T Q, Liu J J. Tribo-metallographic behavior of high carbon steels in dry sliding: I. Wear mechanisms and their transition. Wear 231(1): 1-11 (1999)

University (PSU) from 2016 to 2017. He has a background in mechanical engineering and surface science. His current research interest includes micro/nano-tribology and nanofabrication. He has published 60 peer-reviewed journal papers and authorized 7 patents. He is a guest associate editor of Frontiers in Chemistry.

nanotribology, ultra-precision surface manufacturing, and nanofabrication and application. He has published more than 200 peer-reviewed journal papers and authorized more than 27 patents. He is the associate editor of Chinese Journal of Mechanical Engineering, and a member of editorial board of eight journals, such as Friction, Frontiers of Mechanical Engineering, and the Proceedings of the Institution of Mechanical Engineers, Part J: Journal of Engineering Tribology. 